\title{
NF- $\kappa B$ and GATA-Binding Factor 6 Repress Transcription of Caveolins in Bladder Smooth Muscle Hypertrophy
}

Chellappagounder Thangavel, ${ }^{*}$ Cristiano M. Gomes, ${ }^{\dagger}$ Stephen A. Zderic, ${ }^{\ddagger}$ Elham Javed, ${ }^{\S}$ Sankar Addya, ${ }^{\llbracket}$ Jagmohan Singh,

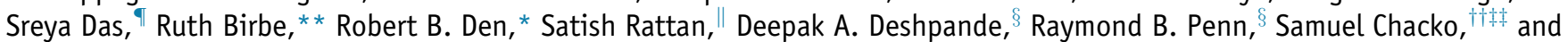
Ettickan Boopathi ${ }^{\uparrow \dagger \dagger}$

From the Department of Radiation Oncology, * the Department of Medicine, ${ }^{\S}$ Center for Translational Medicine, the Kimmel Cancer Centre, $₫$ and the Division of Gastroenterology and Hepatology, "Department of Medicine, Thomas Jefferson University, Philadelphia, Pennsylvania; the Division of Urology, ${ }^{\dagger}$ University of Sao Paulo School of Medicine, Hospital das Clinicas, University of São Paulo School of Medicine, São Paulo, Brazil; the Department of Urology, ${ }^{\ddagger}$ Children’s Hospital of Philadelphia, Philadelphia, Pennsylvania; the Department of Pathology and Laboratory Medicine, ${ }^{* *}$ Cooper University Health Care, Camden, New Jersey; and the Division of Urology ${ }^{\dagger \dagger}$ and the Department of Pathobiology, ${ }^{\ddagger}$ University of Pennsylvania, Philadelphia, Pennsylvania

\author{
Accepted for publication \\ December 17, 2018. \\ Address correspondence to \\ Ettickan Boopathi, Ph.D., \\ Room \#541, Center for Trans- \\ lational Medicine, Department \\ of Medicine, Jefferson Alumni \\ Hall, 1020 Locust Street, \\ Thomas Jefferson University, \\ Philadelphia, PA 19107. E- \\ mail: boopathi.ettickan@ \\ jefferson.edu.
}

\begin{abstract}
Caveolins (CAVs) are structural proteins of caveolae that function as signaling platforms to regulate smooth muscle contraction. Loss of CAV protein expression is associated with impaired contraction in obstruction-induced bladder smooth muscle (BSM) hypertrophy. In this study, microarray analysis of bladder RNA revealed down-regulation of CAV1, CAV2, and CAV3 gene transcription in BSM from models of obstructive bladder disease in mice and humans. We identified and characterized regulatory regions responsible for CAV1, CAV2, and CAV3 gene expression in mice with obstruction-induced BSM hypertrophy, and in men with benign prostatic hyperplasia. DNA affinity chromatography and chromatin immunoprecipitation assays revealed a greater increase in binding of GATA-binding factor 6 (GATA-6) and NF- $K B$ to their cognate binding motifs on CAV1, CAV2, and CAV3 promoters in obstructed BSM relative to that observed in control BSM. Knockout of NF- $\kappa B$ subunits, shRNA-mediated knockdown of GATA-6, or pharmacologic inhibition of GATA-6 and NF- $K B$ in BSM increased CAV1, CAV2, and CAV3 transcription and promoter activity. Conversely, overexpression of GATA- 6 decreased CAV2 and CAV3 transcription and promoter activity. Collectively, these data provide new insight into the mechanisms by which CAV gene expression is repressed in hypertrophied BSM in obstructive bladder disease. (Am J Pathol 2019, 189: 847-867; https://doi.org/10.1016/j.ajpath.2018.12.013)
\end{abstract}

Caveolae are 50- to 100-nm (diameter) flask-shaped invaginations of the cell plasma membrane; they contain high levels of sphingolipids and cholesterols, and are present in muscle, endothelia, and adipocytes. ${ }^{1-3}$ Caveolae have been shown to be necessary for multiple cellular processes, which include transcytosis, lipid metabolism, and receptor trafficking. ${ }^{3,4}$ Caveolins (CAVs) are a family of $21-$ to $24-\mathrm{kDa}$ integral membrane proteins involved in the formation of caveolae-rich membrane domains ${ }^{5}$ with three mammalian isoforms identified as CAV1, CAV2, and CAV3. ${ }^{5}$ CAV1 and CAV2 are widely expressed, whereas CAV3 is found predominantly in skeletal, cardiac, and smooth muscle cells (SMCs). ${ }^{5}$ All three isoforms of CAV proteins are detected in bladder smooth muscle (BSM). ${ }^{6}$ Caveolae are also characterized by the presence of recently described cavin family members; interaction of CAV1 and cavin-1 at the plasma membrane is required for caveolae formation. ${ }^{7,8}$ Previous studies have established that these specialized lipid microdomains are involved in the compartmentalization of several signaling elements, such as growth factors, G-protein-coupled receptors, Src family protein kinases, and

Supported by NIH grants R01DK100483 (E.B.) and R01NIDDK035385 (S.R.); and Thomas Jefferson University Sidney Kimmel Cancer Center grant 5P30CA056036-17.

Disclosures: None declared. 
nitric oxide synthases, all of which can interact with CAV proteins and with caveolae., ${ }^{9,10}$

Previous studies have suggested a role for caveolae in smooth muscle signaling, and loss of CAV1 in these cells leads to failure of caveolae formation. ${ }^{11}$ Both CAV1 and CAV3 can induce caveolae formation, whereas CAV2 requires CAV1 to reach the plasma membrane. ${ }^{2,12} \mathrm{CAV} 3$ is required for the assembly of membrane caveolae. ${ }^{13} \mathrm{CAV} 2$ interacts with CAV1 and forms hetero-oligomeric complexes within caveolae. All three isoforms of CAV genes are expressed in bladder and vascular SMCs. CAV1, CAV2, and CAV3 proteins interact with each other to form an oligomeric complex that lines the membranes and provides structural stability to the inverted $\omega$-shaped membrane invaginations. ${ }^{14}$ Loss of $C A V 1$ gene expression has been shown to impair smooth muscle contraction in bladder and airways. ${ }^{14-16}$ Loss of CAV1 is associated with disruption of M3 muscarinic acetylcholine receptor activity in bladder and serotonergic and cholinergic activity in airways. ${ }^{16,17}$ CAV3 expression is associated with contractile protein expression in rat aortic SMCs, and loss of CAV3 is associated with down-regulation of myocardin, which has been shown to be important for the smooth muscle contractile phenotype. ${ }^{18,19}$ Caveolae modulate receptor-mediated contractile responses in the bladder, and the expression of all three CAV proteins in BSM supports a central role for caveolae in the regulation of selective G-protein-coupled receptor signaling. ${ }^{14,17,20}$ Earlier studies have described loss of CAV1, CAV2, and CAV3 expression in BSM from mice, rabbit, and human with partial bladder outlet obstruction (PBOO) and in aged rat bladders. ${ }^{21-23}$ Thus, it is possible that the decreased BSM contraction observed in obstructed bladder could be due to loss of CAV protein expression in these tissues.

Given the clear effect of reduced CAV protein expression in regulating BSM contraction, loss of CAV gene expression is anticipated to have significant impact in the pathophysiology of the BSM. Although several studies have described changes in CAV protein expression under various pathologic conditions, ${ }^{21-23}$ the mechanisms responsible for mediating these changes in smooth muscle have not been elucidated. Therefore, it is important to understand the transcriptional regulation of CAV genes and elucidate the mechanism of CAV gene repression during BSM remodeling in $\mathrm{PBOO}$ either induced surgically in mice or caused by benign prostatic hyperplasia $(\mathrm{BPH})$ in men. Identifying the transcriptional machinery critical for CAV gene transcription may also be useful in regenerative medicine for tissue engineering using stem cells. Herein, we identified and characterized regulatory regions responsible for $C A V 1, C A V 2$, and $C A V 3$ gene expression in BSM from models of obstructive bladder disease in mice and humans using a combination of protein purification by DNA affinity chromatography, mutational analysis, chromatin immunoprecipitation (ChIP), and promoter reporter assay. Herein, we demonstrate, for the first time, that GATA and $\kappa \mathrm{B}$ motifs are required for CAV promoter repression, and GATA-binding factor 6 (GATA-6) and
NF- $\kappa \mathrm{B}$ repress $C A V 1, C A V 2$, and $C A V 3$ gene expression through their cognate binding sites on these promoters. Moreover, both in a mouse model of PBOO as well as in men with BPH-induced PBOO, enhanced binding of GATA-6 and $\mathrm{NF}-\kappa \mathrm{B}$ to GATA and $\kappa \mathrm{B}$ motifs on CAV promoters in hypertrophic BSM was evident and shown to be associated with the loss of CAV gene expression. Furthermore, both in vitro cell culture and in vivo mouse models were used to examine the effects of small-molecule inhibitors of NF- $\kappa \mathrm{B}$ and GATA-6 on CAV gene expression. We demonstrate, for the first time, that GATA-6 inhibitor, K-7174, and NF- $\kappa$ B inhibitor, BAY 11-7082, up-regulate $C A V 1, C A V 2$, and $C A V 3$ mRNA and protein expression in human BSM cells. Most important, i.p. administration of small-molecule inhibitors of NF- $\kappa \mathrm{B}$ and GATA-6 increase $C A V 1, C A V 2$, and $C A V 3$ mRNA and protein expression in murine BSM tissue. Being transcriptional repressors of $C A V 1, C A V 2$, and $C A V 3$ gene transcription, GATA- 6 and NF- $\kappa$ B are likely involved in the suppression of all three CAV genes in PBOO-induced BSM hypertrophy in men and in mice. Identification of GATA-6 and NF- $\mathrm{B}$ as key regulatory molecules involved in CAV gene repression in obstructive disease implicates these proteins as potential targets for therapeutic intervention.

\section{Materials and Methods}

\section{Surgical Induction of PBO0 in the Mouse Model}

All animal studies were performed with approval from the Institutional Animal Care and Use Committees at the Children's Hospital of Philadelphia (Philadelphia, PA) and the University of Pennsylvania (Philadelphia, PA). All animal experiments were performed in compliance with the standards for care and use of animals, as affirmed in the Guide for the Care and Use of Laboratory Animals, ${ }^{24}$ published by the NIH (Bethesda, MD). Partial surgical ligation of the urethra was performed on adult male mice, as described previously. ${ }^{25}$ The identical procedure was followed for sham-operated animals until the suture was tied down, and then the suture was removed and the abdomen was closed. Mice were euthanized at 2 weeks of PBOO, the bladders were harvested, the mucosa and serosa were removed from the muscle layer, and the muscle tissue was snap frozen in liquid nitrogen for biochemical and molecular biological studies.

\section{RNA Preparation and RT-PCR}

RNA was isolated from sham and PBOO murine BSM using a TRIzol Plus RNA Purification System (Life Technologies Corp., Carlsbad, CA), as per the manufacturer's direction. An RNeasy minikit (Qiagen, Germantown, MD) was used to purify the RNA. An Agilent bioanalyzer (Agilent Technologies, Inc., Santa Clara, CA) with an RNA 6000 nanochip was used to determine the quality of RNA. Reverse transcription of total RNA to cDNA was performed using HighCapacity cDNA Reverse Transcription Kits (Applied 
Biosystems, Foster City, CA), as per the manufacturer's instruction.

\section{Microarray}

Microarray experiments of bladder tissue RNA from shamoperated control and PBOO mice were performed using Illumina Genome-Wide Expression Bead Chips (MouseWG-6 version 2.0 Expression Bead Chip; Illumina, San Diego, CA). The chips were scanned after completion of hybridization by the Illumina bead array scanner. Illumina microarray data were analyzed by Genome Studio 3.0 and GeneSpring 14.4 software (Agilent Technologies, Inc.). Differentially expressed genes (DEGs) between sham and PBOO mice were identified using GeneSpring GX 14.4 on the basis of a $P$ value $(P \leq 0.05)$. The microarray data from the intensity data (IDAT) file were exported to Microsoft Excel (Microsoft, Redmond, WA), and the data were analyzed at the Cancer Genomics Centre of Thomas Jefferson University (Philadelphia, PA). The fold ratio between $\mathrm{PBOO}$ and sham-operated control was generated using the average of normalized gene expression values of two biological replicates of each group. Differentially expressed genes were chosen as candidates for further studies based on the statistical significance of $P \leq 0.05$ using the $t$-test (unpaired) and subsequently limited by an absolute fold change of $\geq 1.4$. A volcano plot was constructed to look at fold change, and statistical significance simultaneously. The probe sets were grouped based on their expression pattern using hierarchical clustering algorithm and heat maps were generated from a differentially expressed gene list. The microarray data were deposited to the National Center for Biotechnology Information's Gene Expression Omnibus database (https://www. ncbi.nlm.nih.gov/geo; accession number GSE107427).

\section{IPA}

Canonical pathways in microarray data analysis were predicted using Ingenuity Pathway Analysis software version 8.0 (IPA; Qiagen; https://www.qiagenbioinformatics. com/products/ingenuity-pathway-analysis, last accessed April 29, 2018). Expression data sets containing gene identifiers (Entrez Gene ID) and their corresponding expression values as fold changes in the mouse bladder from sham and PBOO groups were uploaded into the IPA. Differentially expressed genes are mapped to genetic networks available in the Ingenuity database in IPA and were then ranked by score. IPA identifies biological networks, functional pathways, and global functions of a particular data set based on the known interaction/relations among target genes/proteins. The relationships between the molecules are represented as a graph, which is also referred to as a network. The nodes in the network represent molecules or genes, and the edge (line) represents the relationship between the molecules or genes. All edges are supported by at least one reference from the literature, from a textbook, or from canonical information stored in the
Ingenuity Pathway Knowledge Base. The intensity of the node color indicates the degree of up-regulation (red) or down-regulation (green). Nodes are shown using various shapes, and these shapes represent the functional class of the gene product.

\section{Human Bladder Samples}

Experiments using human bladder tissues were approved by the University of Pennsylvania Institutional Review Board (approval number 803645). Frozen human bladder tissue samples (collected through University of São Paulo School of Medicine institutional review board protocol number 811/04) were obtained from the University of São Paulo (São Paulo, Brazil) by C.M.G. Bladder tissue biopsy specimens were collected from patients, aged 62 to 78 years, who underwent suprapubic prostatectomy to treat BPH. All patients had severe lower urinary tract symptoms and were preoperatively characterized as having overt bladder outlet obstruction. Bladder outlet obstruction was assessed via multichannel urodynamics using the bladder outlet obstruction index. A detailed description of BSM obtained from control and BPH patients has been published previously. ${ }^{22,26}$ Control samples were acquired from patients undergoing ureteral reimplantation and from nondiseased bladder tissue from patients with bladder cancer undergoing cystectomy. The reasons for ureteral reimplantation in the control group were distal ureteral stenosis and vesicoureteral reflux in one patient each. No patients in the control group exhibited lower urinary tract symptoms. They all had an American Urological Association symptom score of $<8$ and had no clinical symptoms of BPH. Agematched control individuals were used for comparison with the BPH group.

\section{Protein Extraction and Immunoblot Analysis}

Serosa and mucosa were removed from murine bladder before the tissue was frozen in liquid nitrogen. Total protein was extracted from the frozen bladder tissue and subjected to Western blot analysis, as previously described. ${ }^{22}$ Briefly, protein samples were separated on SDS-PAGE and transferred to polyvinylidene difluoride membranes (Millipore, Bedford, MA). The membranes were probed with the following primary antibodies: anti-rabbit CAV1, CAV2, and CAV3, NF-кB c-Rel, and GATA-6 (Abcam, Cambridge, MA), and NF-KB p50 (Santa Cruz Biotechnology, Dallas, TX). Membranes were washed with phosphate-buffered saline/Tween before incubation with species-specific secondary antibodies. Target proteins were visualized using enhanced chemiluminescence, as described previously. ${ }^{22}$ Equal loading of the protein was confirmed by probing the membranes with anti-glyceraldehyde-3-phosphate dehydrogenase antibody (Abcam). Bands on the immunoblot were quantified by densitometry using an Alpha Innotech FluroChem 8800 Image system (ProteinSimple, San Jose, CA). 
Cloning, Plasmid Construct Preparation of Primary BSM Cells, Transient Transfection, and Promoter Activity Assays

The $5^{\prime}$ upstream promoter regions of $C A V 1(1.3 \mathrm{~kb}), C A V 2$ $(1.0 \mathrm{~kb})$, and $C A V 3(1.0 \mathrm{~kb})$ were isolated from human genomic DNA. The PCR product amplified from human genomic DNA using the gene-specific primers was cloned into pGL-4 basic luciferase reporter vector (pGL-4.1; Promega, Madison, WI). Specific mutations were introduced within the CAV promoters using the Quick-change site-directed mutagenesis kit (Stratagene, La Jolla, CA). Mutations were generated at the $\kappa \mathrm{B}$ and GATA binding site in the human $C A V 1, C A V 2$, and $C A V 3$ promoters, yielding the mutant constructs, as per the manufacturer's direction (Stratagene). Adenovirus expressing GATA-6 and NF- $\kappa$ B protein was obtained from Vector Biolabs (Malvern, PA).

Primary BSM cells were prepared from mouse bladders, as described previously. ${ }^{22}$ Briefly, the BSM was dissected into small pieces after removing the urothelial and serosal layers from 8-week-old mice. Collagenase (Sigma-Aldrich Co, St. Louis, MO), was used to dissociate the cells from the muscle tissue, and the isolated cells were cultured in smooth muscle growth medium-2 (Lonza Walkersville, Inc., Walkersville, MD). Isolated cells were identified as SMCs by the presence of smooth muscle myosin heavy chain and smooth muscle 22 (SM22) using immunofluorescence and immunoblot analyses. Human primary BSM cells were obtained from Lonza Walkersville, Inc. Transfection of murine and human BSM cells was performed by electroporation using Amaxa Nucleofector II (Lonza Walkersville, Inc.), as per the manufacturer's instructions. Renilla luciferase reporter plasmid (pRL-SV40) was cotransfected with firefly luciferase promoter reporter construct in all transfections of murine and human BSM cells as an internal control for assessing variations in transfection efficiency. pGL-4 basic vector without the promoter insert was used as a negative control for firefly luciferase promoter reporter (pGL-4 promoter reporter constructs). At the end of the experiment, cell lysates were prepared, and both firefly and Renilla luciferase activities were measured with the DualLuciferase Reporter Assay system (Promega).

\section{Bioinformatics Analysis}

The TATA box in the human $C A V 3$ promoter was predicted using the Matrix Family Library version 8.4 of Genomatix MatInspector software version 8.0 (Intrexon Bioinformatics Germany GmbH, Munich, Germany; http://www.genomatix. delonline_help/help_matinspector/matinspector_help.html). Bioinformatics program AliBaba2 version 2 (GeneXplain $\mathrm{GmbH}$, Wolfenbüttel, Germany; http://gene-regulation. com/pub/programs/alibaba2/index.html), which uses the Transcription Factor Database (http://gene-regulation.com/ pub/programs.html), was used to identify GATA-6 and $\mathrm{NF}-\kappa \mathrm{B}$ transcription factor binding sites on the $C A V 2$ and $C A V 3$ promoters.

\section{DNA Affinity Column Chromatography}

A promoter pull-down approach was used to identify NF- $\kappa$ B and GATA-6 transcription factor binding sites on $C A V 2$ and $C A V 3$ promoters. The DNA affinity column was prepared, as described previously. ${ }^{27}$ To maximize the DNA binding to the affinity column, the human $C A V 2$ and $C A V 3$ promoters were subdivided into three smaller regions ( 1 to $-350,-350$ to -700 , and -700 to $-1000 \mathrm{bp}$ ). PCR-amplified promoter regions were end labeled with $\mathrm{T} 4$ polynucleotide kinase and were coupled to cyanogen bromide-activated Sepharose 4B (Sigma-Aldrich) individually, as described previously. ${ }^{22,28}$ Nuclear extracts from sham and PBOO murine BSM tissue were prepared, as previously described, ${ }^{29}$ and $1 \mathrm{mg}$ of nuclear protein was loaded onto a DNA affinity column ${ }^{27}$ and the DNA-bound proteins were eluted with an elution buffer containing progressive salt gradient $(0.25,0.5,0.75$, and 1 $\mathrm{mol} / \mathrm{L} \mathrm{KCl}$ ). The eluted fractions were assayed for GATA-6 and NF- $\kappa \mathrm{B}$ binding to their consensus DNA oligonucleotides by transcription factor enzyme-linked immunosorbent assay (TF-ELISA; Active Motif, Carlsbad, CA), as per the manufacturer's instructions.

\section{ChIP}

A ChIP assay was performed on BSM isolated from sham and PBOO mice and BSM from men with or without BPHinduced obstruction, as previously described ${ }^{30}$ Chromatin samples, ranging from 200 to $600 \mathrm{bp}$, were incubated with

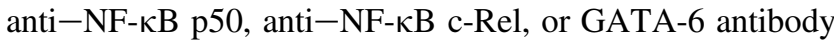
(Abcam) or normal rabbit IgG (Santa Cruz Biotechnology) overnight at $4^{\circ} \mathrm{C}$; and the protein-DNA complex was immunoprecipitated using protein A agarose beads (Sigma-Aldrich Co). The immunoprecipitated complexes were washed, the protein-DNA cross-link was reversed, and the DNA was eluted, as previously described. ${ }^{30}$ As an input control, an aliquot of sheared chromatin was purified using the QIAquick PCR purification kit (Qiagen, Valencia, CA). The DNA associated with this complex was then purified and identified by PCR. DNA band intensities were quantified from the agarose gels by densitometry using an Alpha Innotech FluroChem 8800 Image system (ProteinSimple). ChIP values were normalized to the total input DNA. Relative enrichments for each region are presented as the percentage of input.

\section{Histology}

For histologic studies, bladders from sham and PBOO mice were fixed in $10 \%$ neutral-buffered formalin at room temperature for at least 24 hours. Bladder sections were subjected to dehydration in graded ethanol, cleared in xylene and embedded in paraffin. Sections (5 $\mu \mathrm{m}$ thick) of paraffinembedded tissue were mounted onto a glass slide and then stained with Masson's trichrome stain using standard techniques (Histology Core, Department of Pathology, Thomas Jefferson University). Stained bladder sections were imaged 
using a Light Microscope BX43 (Olympus, St. Louis, MO) with a $40 \times$ objective lens.

\section{Immunofluorescence and Confocal Microscopy}

Frozen sections ( $5 \mu \mathrm{m}$ thick) of bladder tissue from sham and PBOO mice were mounted onto glass slides, and the slides were processed, as previously described, for the immunofluorescence. $^{22}$ The slides were incubated with anti-rabbit CAV3 antibody (Abcam), followed by anti-goat SM22 antibody (Abcam). Slides were washed with phosphate-buffered saline/ Tween before adding the species-specific secondary antibodies (anti-rabbit Cy3 and anti-goat Alexa Fluor 488; Invitrogen, St. Louis, MO). SM22 was used to localize the CAV3 protein to smooth muscle in the bladder tissue. VectaShield mounting medium (Vector Laboratories, Inc., Burlingame, CA) was used to mount the samples. Samples were imaged at room temperature using a high-resolution laser-scanning confocal microscope (Fluoview FV 1000; Olympus) with a $60 \times$ objective oil immersion, numerical aperture 1.45 lens. Images were acquired as series of Z-stacks using Fluoview FV10-ASW software version 4.2 (Olympus), and the acquired Z-stack images were imported into ImageJ version 1.0 using LOCI Bio-Formats (NIH). Red and green colors were assigned to $\mathrm{Cy} 3$ and fluorescein isothiocyanate fluorescence, respectively.

\section{GATA-6 Knockdown by RNA Interference}

Predesigned GATA-6-specific shRNA lentivirus particles (sc-37907-V) were used to knock down the endogenous GATA6 gene expression. ${ }^{22}$ Scrambled shRNA (sc-108080; Santa Cruz Biotechnology) was used as a control. For this, human BSM cells were transduced with GATA-6-specific shRNA and scrambled shRNA lentivirus particles for 72 hours, and total cell lysates and RNA were prepared for the evaluation of knockdown efficiency by immunoblot and RT-PCR. In cotransfection experiments, $C A V 1, C A V 2$, and $C A V 3$ promoter reporter plasmids were introduced into BSM cells via electroporation.

\section{NF- $\kappa B$ KO Mice}

Dr. Christopher Hunter (Department of Pathobiology, University of Pennsylvania) provided NF- $\kappa \mathrm{B}$ p50 and NF- $\kappa \mathrm{B}$ c-Rel knockout (KO) mice. The NF- $\kappa \mathrm{B}$ c-Rel mice were originally from Dr. Hsiou-Chi Liou (Division of Immunology, Department of Medicine, Weill Medical College of Cornell University, New York, NY).

Treatment of BSM Cells with Small-Molecule Inhibitor of GATA- 6 and NF- $\kappa B$

Human BSM cells were incubated with dimethyl sulfoxide (vehicle), $5 \mu \mathrm{mol} / \mathrm{L} \mathrm{K}-7174$ (MedKoo Biosciences Inc., Morrisville, NC), or $10 \mu \mathrm{mol} / \mathrm{L}$ BAY 11-7082 (MilliporeSigma, Burlington, MA) for 48 hours, as described previously. ${ }^{31,32}$ The specificity of K-7174 and BAY 11-7082 in inhibiting GATA and NF- $\mathrm{BB}$ DNA binding activity, respectively, has been established previously. ${ }^{32,33}$

\section{Treatment of Mice with Small-Molecule Inhibitor of} GATA- 6 and NF- $\kappa$ B

The Institutional Animal Care and Use Committees at Thomas Jefferson University approved all animal studies reported herein. All animal studies were performed in accordance with the Guide for the Care and Use of Laboratory Animals, ${ }^{24}$ published by the NIH. Ten-week-old male C57BL/6J mice (The Jackson Laboratory, Bar Harbor, $\mathrm{ME})$ received a daily single-dose i.p. injection of K-7174 (MedKoo Biosciences Inc.) or BAY 11-7082 (MilliporeSigma) at $30 \mathrm{mg} / \mathrm{kg}$ in $0.1 \mathrm{~mL}$ normal saline for 9 consecutive days, as described previously. ${ }^{31,34}$ Control mice were treated with $0.1 \mathrm{~mL}$ of normal saline containing $1 \%$ dimethyl sulfoxide. At the end of the treatment, bladders were harvested and processed for RNA and protein isolation.

\section{Statistical Analysis}

GeneSpring software version 14.5 (Agilent Technologies, Inc.) was used for microarray data analyses. An unpaired $t$ test was used for the comparison between the groups. A statistical threshold of $P<0.05$ with fold change $\geq 1.4$ was considered as significant for identification of differentially expressed genes. The probe set signals were calculated with the Iterative Plier 16 summarization algorithm; baseline to median of all samples was used as baseline option. A $t$-test was used for comparisons between experimental groups.

\section{Results}

\section{Differential Expression of Genes between Sham and PB00 Mice}

Mice subjected to PBOO exhibited increased mean bladder weights and bladder/body weight ratio compared with sham-operated animals (Figure 1A). Histology analysis by Masson's trichrome staining revealed a significant increase in the collagen deposition in between the muscle bundles in obstructed bladder (Figure 1B). Hierarchical clustering displayed the different gene expression patterns between these two groups, and the results of selected 27 genes that were differentially expressed (both up-regulated and downregulated genes) with $\geq 1$.4-fold change (false-discovery rate of $0.01 \%$ and $P \leq 0.05$ ) in obstructed bladder from PBOO mice compared with sham-operated control are shown in Figure 1C and Table 1. A list of all 368 genes that were differentially expressed between sham and PBOO murine bladder with $\geq 1$.4-fold change and the volcano plot that displays both fold change ( $\geq 1$.4-fold) and statistical significance $(P \leq 0.05)$ of the DEG are shown in Supplemental Table S1 and Supplemental Figure S1, 
A

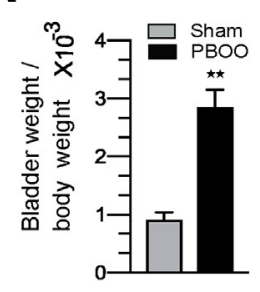

B

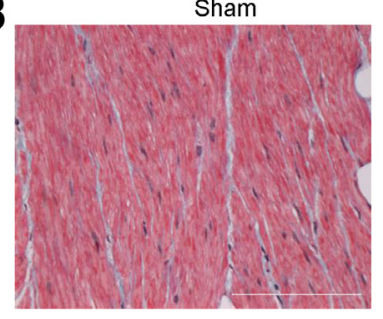

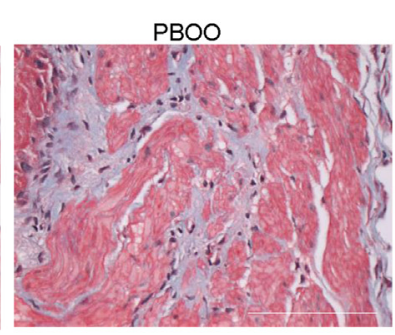

E

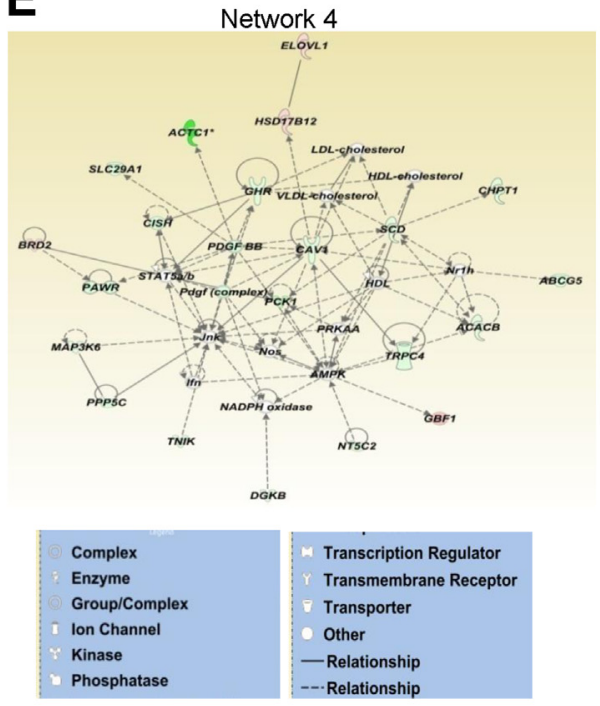

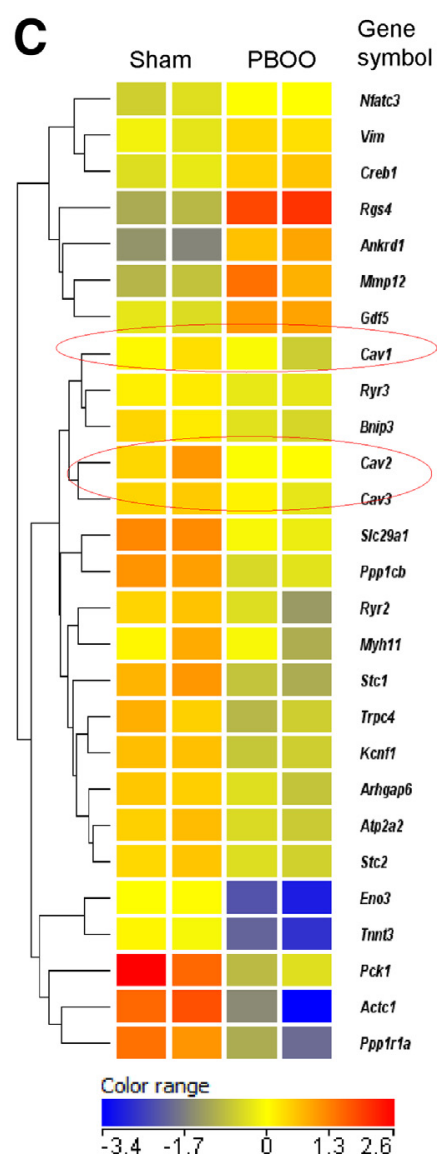

D

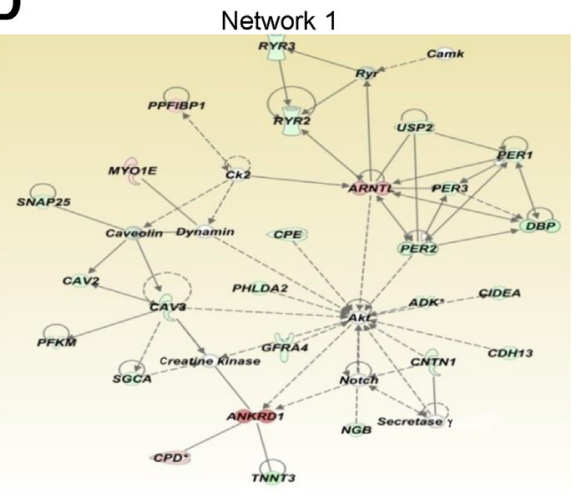

Transcription regulator
Y Transmembrane receptor
- Transporter
Other
- Relationship
-- Relationship

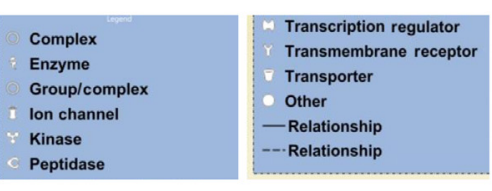

Figure 1 Genome-wide expression profile of mRNA in sham and PB00 mice. A: Body weights of mice were recorded before they were euthanized at 2 weeks after surgery. Bladder weights were measured after the mice were sacrificed. B: For histologic studies, sections ( $5 \mu \mathrm{m}$ thick) of urinary bladders from sham and PB00 mice were subjected to Masson trichrome staining. Stained bladder sections were imaged using a Light Microscope BX43 with a $40 \times$ objective lens. C: Heat map: hierarchical clustering performed on the mRNA samples of sham and PB00 mice. Heat map using average-linkage hierarchical clustering was generated, and the cluster image shows the trend of gene expression levels in the bladder smooth muscle of sham and PB00 mice. The dendrogram illustrates the clustering tree resulting from hierarchical clustering of gene expression values. Each row corresponds to a single mRNA probe. The colored bar at the bottom of the panel represents changes on a linear scale, where green and red represent down-regulated and up-regulated gene expression, respectively. Red ovals denote the expression levels of CAV1, CAV2, and CAV3 genes in sham and PB00 mice bladder. D and E: Interaction networks identified with differentially expressed genes. Two of the five top-ranked networks (networks 1 and 4) are shown, which identify CAV genes as the interacting partners. Genes are represented as nodes, and the biological relationships between two nodes are represented as a line: genes up-regulated in PB00 bladder are colored in shades of red; down-regulated genes in PBO0 are colored in green, and the genes in gray were not differentially expressed. Intensity of the node color indicates the degree of up-regulation (red) or down-regulation (green). Nodes are displayed using various shapes that represent the functional class of the gene product. Meanings of node shapes and edges are indicated in the legend within the figure. Edges are displayed with various labels that describe the nature of the relationship between the nodes. Solid lines indicate direct interactions; dashed lines, indirect interactions; lines without an arrowhead, binding only; lines with an arrowhead, acts on. The length of an edge reflects the evidence supporting the node-to-node relationship, in that edges supported by an article from the literature are shorter. Data are expressed as means \pm SD (A). $n=11$ sham and PB00 mice $(\mathbf{A}) .{ }^{*} P<0.01$ versus control. Scale bars $=500 \mu \mathrm{m}(\mathbf{B})$.

respectively. There was a significant down-regulation of $C A V 1, C A V 2$, and $C A V 3$ genes in obstructed murine bladder compared with sham-operated control. Similar to findings obtained using a rabbit model,${ }^{35-37}$ these mice showed loss of ryanodine receptor (RYR) 2, RYR3, and ATPase expression, as assessed by microarray (Table 1 ).

\section{Elucidation of Interactions among Differentially Expressed Genes}

To investigate the biological interactions of DEG, data sets representing 368 genes with altered expression profile of $\geq 1$.4-fold change, derived from microarray analyses, were imported into the IPA. In the IPA, networks of potentially interacting proteins were identified and placed into nodeedge diagrams composed of focus molecules (microarrayidentified genes) and other interacting molecules. IPA revealed there were five different high-scoring (score $>28$ ) networks associated with 368 DEGs between sham and PBOO mice BSM. Significant IPA networks and the associated molecules are presented in Figure 1, D and E, and Supplemental Table S2. Two of the networks (networks 1 and 4) among these five high-scoring networks associated with DEG represented CAV-mediated signaling (CAV1, CAV2, and CAV3). Network 1 includes interactions of CAV (CAV1, CAV2, and CAV3) genes with genes encoding 
Table 1 Annotated 27 Gene Transcripts Differentially Expressed between Sham and PB00 Murine Bladder

\begin{tabular}{|c|c|c|c|c|}
\hline Probe identification & Gene symbol & Gene name & $P$ value & Fold (up/down) \\
\hline 2970711 & Rgs4 & Regulator of G-protein signaling 4 & 0.001929974 & +7.937988 \\
\hline 2060121 & Arhgap6 & $\rho$ GTPase-activating protein 6 & 0.02501308 & -2.18611 \\
\hline 4150180 & Ppp1cb & Protein phosphatase 1 , catalytic subunit, $\beta$ isoform & 0.004460794 & -2.78077 \\
\hline 2650687 & Kcnf1 & Potassium voltage-gated channel, subfamily $F$, member 1 & 0.001593646 & -2.56219 \\
\hline 6040022 & Trpc4 & $\begin{array}{l}\text { Transient receptor potential cation channel, } \\
\text { subfamily C, member } 4\end{array}$ & 0.023744632 & -2.73619 \\
\hline 1660156 & Ryr3 & Ryanodine receptor 3 & 0.003367557 & -1.41486 \\
\hline 1090075 & Atp2a2 & ATPase, $\mathrm{Ca}^{2+}$ transporting, cardiac muscle, slow twitch 2 & 0.016132275 & -2.2555 \\
\hline 360161 & Stc1 & Stanniocalcin 1 & 0.01324006 & -3.61698 \\
\hline 4920601 & Stc2 & Stanniocalcin 2 & 0.013560593 & -2.02466 \\
\hline 1570239 & Tnnt3 & Troponin T3 & 0.02173518 & -5.1447 \\
\hline 5130563 & Cav2 & Caveolin 2 & 0.15194602 & -1.6654 \\
\hline 1770519 & Cav3 & Caveolin 3 & 0.12829952 & -1.49647 \\
\hline 7100273 & Myh11 & Myosin heavy chain 11 , smooth muscle & 0.23286378 & -2.07326 \\
\hline 2340021 & Actc1 & Actin, $\alpha$ & 0.047266956 & -19.5778 \\
\hline 104150180 & Vim & Vimentin & 0.02395465 & 1.535159 \\
\hline 100060672 & Gdf5 & Growth differentiation factor 5 & 0.003577606 & 2.60079 \\
\hline 4920070 & Mmp12 & Matrix metalloproteinase 12 & 0.027093915 & 4.050251 \\
\hline 5270136 & Eno3 & Enolase $3 \beta$ & 0.018464409 & -6.263 \\
\hline 7000358 & Pck1 & Phosphoenolpyruvate carboxykinase 1 & 0.04156202 & -6.65625 \\
\hline 3140270 & Bnip3 & BCL2/adenovirus E1B 19-kDa interacting protein 1 & 0.027879694 & -1.72551 \\
\hline 106860154 & Slc29a1 & Solute carrier family 29 nucleoside transporter member 1 & 0.002923535 & -2.58568 \\
\hline
\end{tabular}

Table displays the genes with their expression level (fold change $\geq 1.4$-fold).

+ , up-regulation of the genes in PB00 bladder versus sham-operated control; -, down-regulation of the genes in PB00 bladder versus sham-operated control; BCL, B-cell lymphoma.

for calcium signaling ( $R Y R 2$ and $R Y R 3$ ) and lipid metabolism. Network 4 displays interactions between the $C A V I$ and the transient receptor potential cation channel 4. These genes are known to affect BSM contraction.

\section{Repression of CAV2 and CAV3 Gene Expression in Obstructed BSM in Mice and in Men with BPH}

Microarray analysis of bladder RNA from sham-operated control and 2-week-old PBOO mice revealed the downregulation of $C A V 1, C A V 2$, and $C A V 3$ gene expression
(Figure 1C and Table 1). The down-regulation of $C A V 2$ and $C A V 3$ gene expression was further confirmed in 2-week-old PBOO mice by RT-PCR and immunoblot analysis. Primers used for this experiment are listed in Table 2. CAV2 and $C A V 3$ mRNA and protein were decreased in murine $\mathrm{PBOO}$ BSM compared with controls; $C A V 2$ and $C A V 3$ mRNA and protein were down-regulated in BSM from the bladders of patients with BPH compared with control human bladders $(P<0.01)$ (Figure 2). Bladder tissue sections from sham and obstructed mice were stained with anti-CAV3 antibody and examined by confocal microscopy. Representative confocal

Table 2 Primers Used in This Study

\begin{tabular}{lll}
\hline Gene name & Forward primer sequence & Reverse primer sequence \\
\hline Human CAV1 & $5^{\prime}$-CTGATCAGTGGGCCTCCAAG-3' & $5^{\prime}-$ TTCTGGGCAAAGGGATGCT-3' \\
Mouse CAV1 & $5^{\prime}$-AGCAGACAAATGGGGGTGAG-3' & $5^{\prime}-$ TGAATAGACACGCTGGCCTC-3' \\
Human CAV2 & $5^{\prime}$-AAAGTTGGATCTGCAGCCAT-3' & $5^{\prime}-$ GAGAATTCCCGCAATGAAGGC-3' \\
Mouse CAV2 & $5^{\prime}$-GGATCTGCAGCCATGCTCTC-3' & $5^{\prime}-$ GCTGAGGGTAGCAAACAGGA-3' \\
Human CAV3 & $5^{\prime}$-GTCTAAAGCCAGGTGGGGCAACA-3' & $5^{\prime}-$ GTCCCTAAAGAGAAAGAGCTCGC-3' \\
Mouse CAV3 & $5^{\prime}$-TCTACTCACTGTGTATCCGCAC-3' & $5^{\prime}-$ TGGCTTTAGCCTTCCCTTCG-3' \\
Human GAPDH & $5^{\prime}$-AAAATCAAGTGGGGCGATGC-3' & $5^{\prime}$-GATGACCCTTTTGGCTCCCC-3' \\
Mouse GAPDH & $5^{\prime}$-GCAGTGGCAAAGTGGAGATTG-3' & $5^{\prime}$-GCCGTTGAATTTGCCGTGAG-3' \\
\hline
\end{tabular}


images obtained from BSM of sham and 2-week-old PBOO mice are shown in Figure 2. CAV3 expression was significantly reduced in BSM from murine PBOO bladders. The loss of CAV3 expression specifically in BSM was further confirmed by costaining the tissue section with SM22 (Figure 2). Collectively, these results confirm that $C A V 2$ and $C A V 3$ gene expression is reduced in mice and in men with $\mathrm{PBOO}$ and that repression of $C A V 2$ and $C A V 3$ gene expression is mediated at the transcriptional level. Also, CAVI gene expression is down-regulated in BSM from obstruction-induced hypertrophy in rabbit and murine models of PBOO and in BPH patients. ${ }^{21,22}$

\section{Structural Features of CAV2 and CAV3 Promoters}

The critical transcription factor binding sites on $C A V 2$ and $C A V 3$ promoters were next studied. Specifically, GATA and $\kappa \mathrm{B}$ motifs were studied on $C A V 2$ and $C A V 3$. The putative GATA-6 and NF- $\kappa \mathrm{B}$ binding sites for human and murine $C A V 2$ and $C A V 3$ promoters are shown in Supplemental Figure S2. Promoter analysis of the $C A V 2$ gene by the TRANSFEC program predicted a TATA-less promoter (Supplemental Figure S2, A and B). The Bioinformatics tool, MatInspector, identified a TATA box in the human CAV3 promoter (Supplemental Figure S2, C and D), and it is conserved in mouse. The translational start site (ATG) was designated as 1 .
PB00 Promotes GATA-6 and NF- $\kappa$ B Binding to GATA and $\kappa B$ Motifs on CAV2 and CAV3 Promoters

A promoter pull-down approach was used to identify the GATA-6 and NF- $\kappa \mathrm{B}$ binding sites on $C A V 2$ and $C A V 3$ promoters to compare the binding intensities of these transcription factors in sham and PBOO BSM. The promoter regions of human $C A V 2$ and $C A V 3$ genes were conjugated to cyanogen bromide-activated Sepharose, and approximately $1 \mathrm{mg}$ nuclear protein from sham and PBOO mouse BSM tissue samples was loaded onto each DNA affinity column. The DNA-bound proteins were eluted with a salt gradient. The fractions eluted with $0.5 \mathrm{~mol} / \mathrm{L} \mathrm{KCl}$ containing elution buffer from the -350 - to -700-bp region of the CAV2 DNA affinity column detected GATA- 6 and NF- $\kappa$ B, as demonstrated by TF-ELISA (Figure 3). In an oligonucleotide competition assay, an excess of wild-type (WT) consensus oligonucleotides $(5 \times, 20 \times$, and $50 \times)$ but not mutant (mutation at GATA and $\kappa \mathrm{B}$ motif) consensus oligonucleotides competed with the oligonucleotide sequence immobilized on the plate for binding to GATA- 6 and NF- $\kappa$ B in the TFELISA (Figure 3). Similarly, the fractions eluted with 0.5 $\mathrm{mol} / \mathrm{L} \mathrm{KCl}$ containing elution buffer from the -350 - to -750-bp region of the CAV3 DNA affinity column detected GATA-6 and NF- $\kappa$ B transcription factors, as demonstrated by TF-ELISA (Figure 4); and the WT sequence but not the mutant consensus oligonucleotides competed with the
A

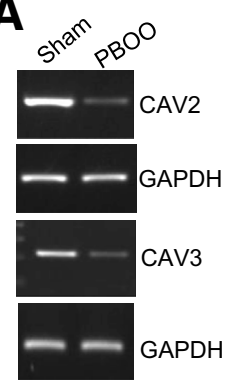

$\mathbf{F}$

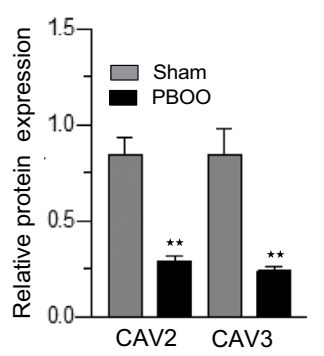

B

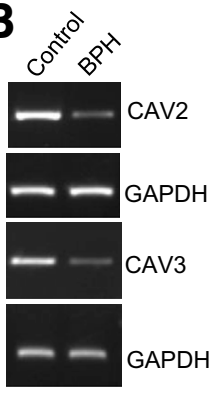

G

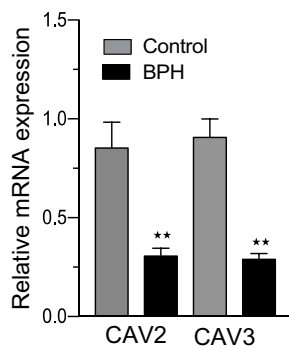

C
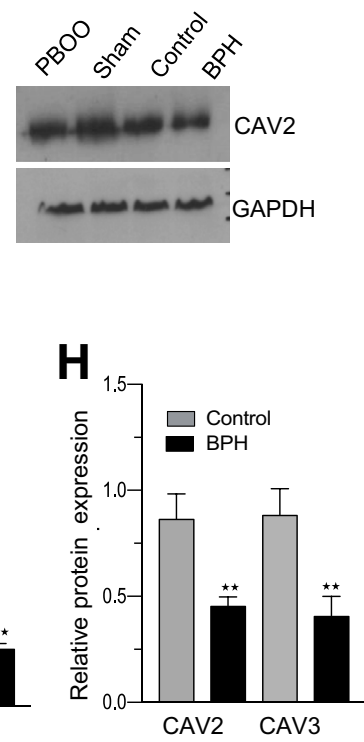

D

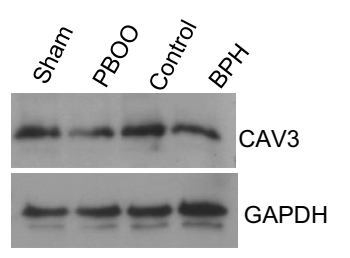

E
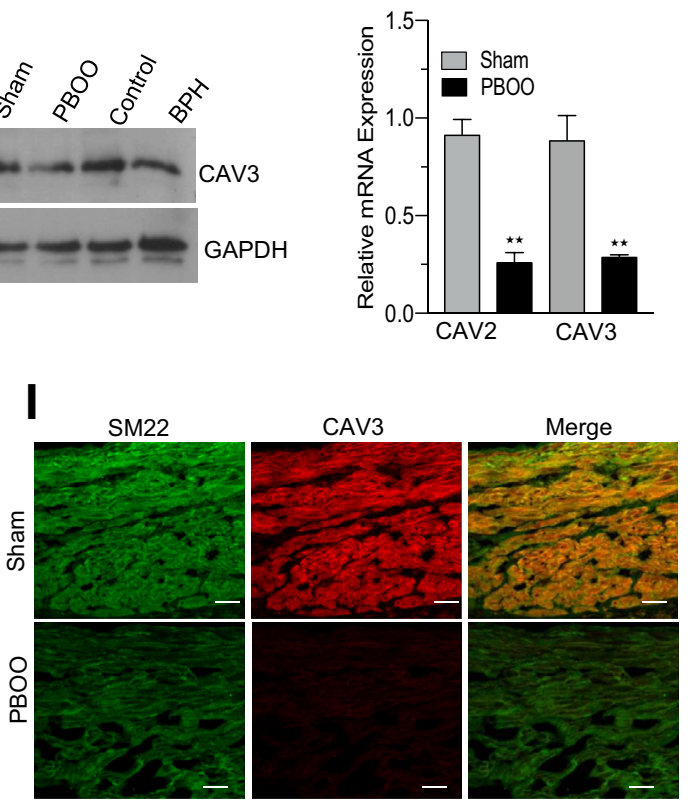

Figure 2 Repression of CAV2 and CAV3 gene expression in murine PB00 and in men with benign prostatic hyperplasia (BPH)-induced bladder outlet obstruction: A-D: RT-PCR (A and B) and immunoblot (C and D) analysis of CAV2 and CAV3 mRNA and protein expression in sham and PB00 mouse and control and BPH patient's bladder smooth muscle (BSM) tissues. Glyceraldehyde-3-phosphate dehydrogenase (GAPDH) served as a loading control. E-H: Quantification of RT-PCR and immunoblot data. I: Murine bladder sections prepared from sham-operated and PB00 mice were stained with anti-CAV3 and anti-smooth muscle 22 (SM22) antibody, followed by Cy3- and fluorescein isothiocyanate-conjugated secondary antibodies. Representative confocal images are shown. Data are expressed as means \pm SD $(\mathbf{E}-\mathbf{H}) . n=8$ sham and PBO0 mouse BSM $(\mathbf{E}-\mathbf{H}) ; n=5$ control and BPH patient tissue $(\mathbf{E}-\mathbf{H})$. ${ }^{*} P<0.01$ versus control. Scale bars $=20 \mu \mathrm{m}(\mathrm{I})$. 
A

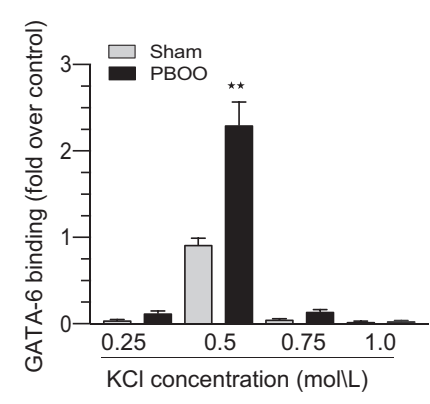

B

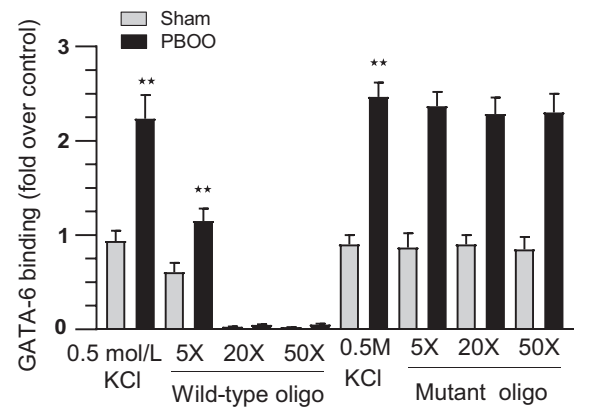

C

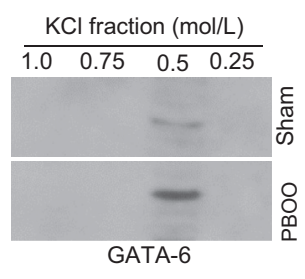

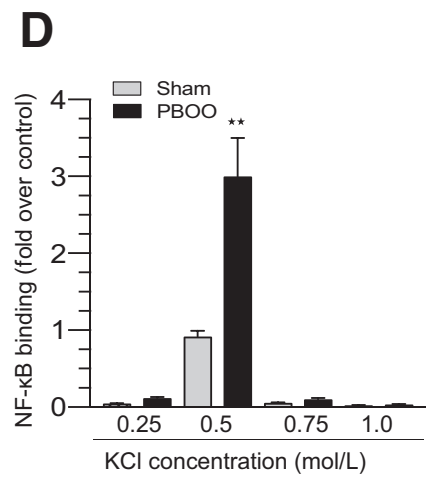

E

$\mathbf{F}$

G

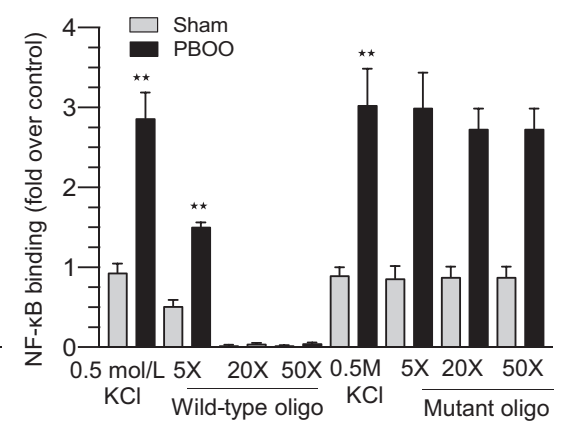

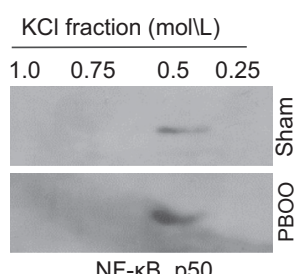

NF-kB p50

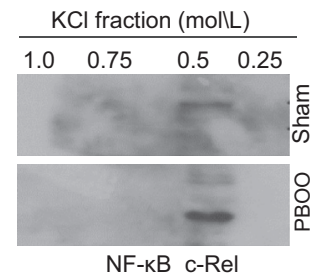

NF-KB c-Rel

Figure 3 PB00 up-regulates GATA-binding factor 6 (GATA-6) and NF- $\kappa$ B binding to CAV2 promoter. Protein fractions, eluted from a -350 - to -700-bp region of CAV2 promoter DNA affinity column, were assayed by transcription factor enzyme-linked immunosorbent assay (ELISA) and immunoblot. A, B, D, and E: GATA-6 (A and $\mathbf{B}$ ) and NF-KB p50 (D and E) binding from sham and PB00 bladder smooth muscle was expressed as absorbance units at $450 \mathrm{~nm}$. Data are representative of at least three independent experiments, each performed in triplicate. B and E: A GATA-6 or NF-KB binding consensus DNA sequence (wild type or mutant) was added in increasing amounts to the ELISA plate in the oligonucleotide competition assay. The $0.5 \mathrm{~mol} / \mathrm{L} \mathrm{KCl}$ denotes the protein fractions eluted from the DNA affinity column using -350- to -700-bp promoter regions of CAV2. C, F, and G: Immunoblot analysis of protein fractions eluted from the -350- to -700-bp region of the CAV2

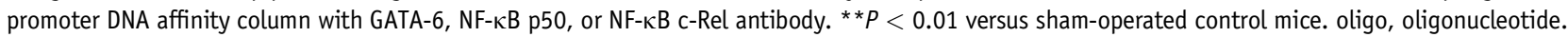

oligonucleotide sequence immobilized on the plate (Figure 4). TF-ELISA and immunoblot analysis revealed the increased binding of GATA- 6 and NF- $\kappa \mathrm{B}$ to their cognate motif on $C A V 2$ and $C A V 3$ promoters, with the nuclear extract isolated from murine PBOO BSM tissues compared with sham-operated control animals (Figures 3 and 4).

The increased binding of GATA-6 and NF- $\kappa \mathrm{B}$ to the GATA and $\kappa \mathrm{B}$ motifs on $C A V 2$ and $C A V 3$ promoters in PBOO mice and in BPH patients was confirmed using a ChIP assay. In these experiments, chromatin samples from control and BPH patients and sham and PBOO mice BSM were precipitated with anti-GATA-6, anti-NF- $\kappa \mathrm{B}$ p50, or anti-NF- $\kappa$ B c-Rel antibody, and subjected to PCR amplification of the GATA and $\kappa \mathrm{B}$ motif in the promoters. Samples immunoprecipitated with anti-GATA-6, anti-NF- $\mathrm{kB}$ p50, or anti-NF- $\kappa \mathrm{B} c-\mathrm{Rel}$ antibody yielded prominent PCR products in obstructed BSM from BPH patients and murine PBOO compared with control human and murine BSM (Figure 5). However, samples immunoprecipitated with preimmune rabbit IgG failed to yield PCR products (Figure 5).

\section{GATA-6 Represses CAV2 and CAV3 Gene Transcription}

Because GATA-6 is recruited to $C A V 2$ and $C A V 3$ promoters in murine and human BSM, the effect of this transcription factor on $C A V 2$ and $C A V 3$ gene expression was next studied. Adenovirus encoding GATA- 6 was introduced into human BSM primary cells by transduction. ${ }^{22}$ Overexpression of GATA-6 in human BSM cells decreased the levels of $C A V 2$ and $C A V 3$ mRNA (Figure 6A) and protein (Figure 6B) relative to the level of control. The expression of $C A V 2$ and $C A V 3$ mRNA and protein increased after knockdown of GATA-6 (Figure 6, C and D). The relative intensities of the bands in Figure 6, A-D, were quantified after normalization with GAPDH and are shown in Figure 6, $\mathrm{E}$ and $\mathrm{F}$. The relative intensities of the bands in Figure 6, I and $\mathrm{J}$, were quantified after normalization with GAPDH and are shown in Figure 6, $\mathrm{K}$ and $\mathrm{L}$. To examine the effect of endogenous GATA-6 gene silencing in regulating $C A V 2$ and CAV3 promoter activity, GATA- 6 shRNA plasmid was cotransfected with $C A V 2$ and $C A V 3$ promoter reporter constructs in primary human BSM cells (Figure $6 \mathrm{G}$ ) via electroporation. Firefly luciferase analysis revealed that the transfection of nonspecific scrambled shRNA did not have any significant effects on $C A V 2$ and $C A V 3$ promoter activities. However, luciferase activity driven by $C A V 2$ and CAV3 promoters was threefold higher in GATA-6 knockdown cells compared with scrambled shRNA-transfected cells (Figure 6G). Transfection analysis of WT and mutant human $C A V 2$ and $C A V 3$ promoters in human BSM cells 

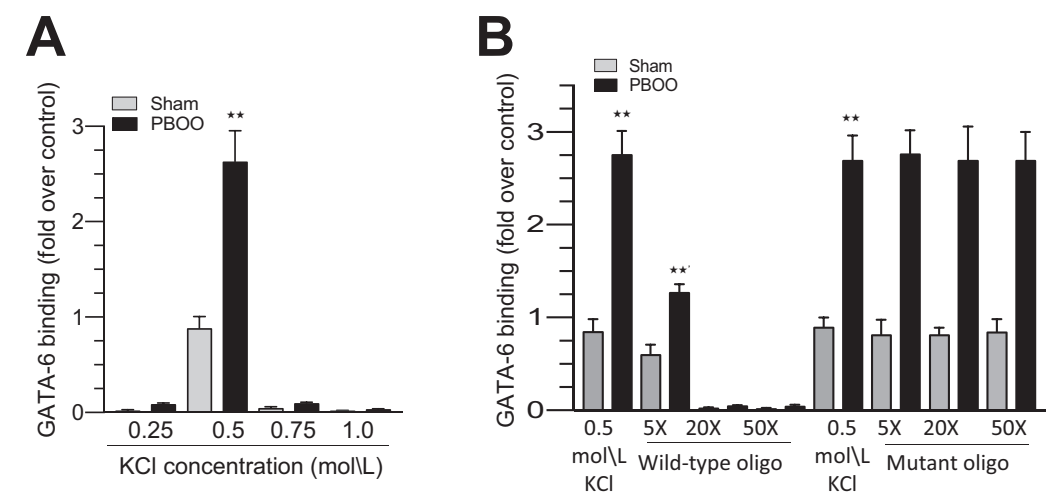

C

E
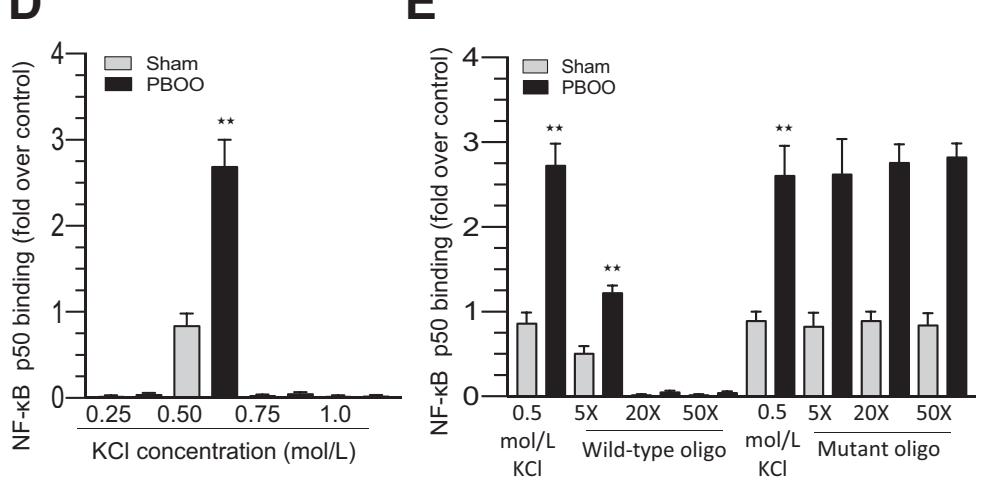

$\mathbf{F}$
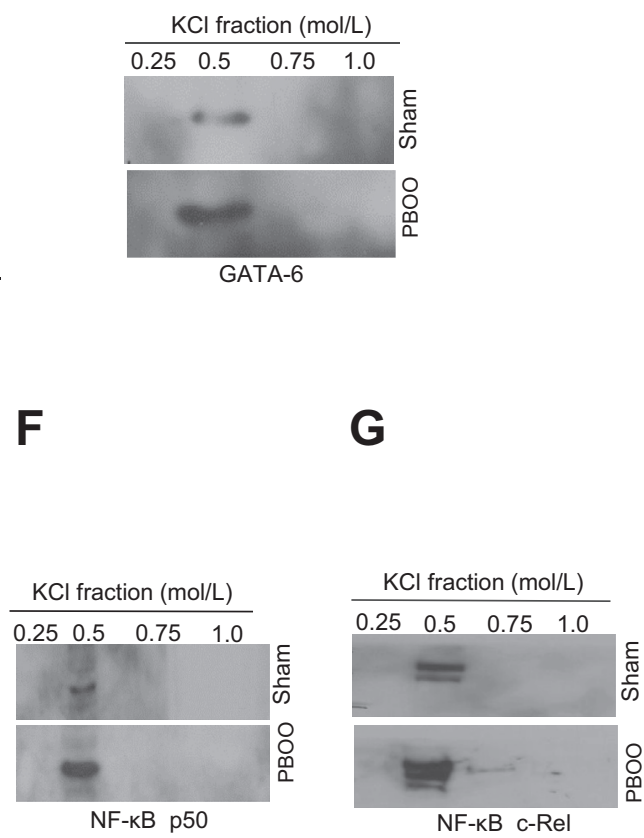

Figure 4 PB00 up-regulates GATA-binding factor 6 (GATA-6) and NF- $K B$ binding to CAV3 promoter. Protein fractions, eluted from a $-350-$ to $-700-b p$ region of the CAV3 promoter DNA affinity column, were assayed by transcription factor enzyme-linked immunosorbent assay (ELISA) and immunoblot. A, B, $\mathbf{D}$, and E: GATA-6 (A and B) and NF-KB p50 (D and E) binding from sham and PB00 bladder smooth muscle was expressed as absorbance units at $450 \mathrm{~nm}$. Data are representative of at least three independent experiments, each performed in triplicate. B and E: In an oligonucleotide competition assay, a GATA-6 or NF- $\kappa$ B consensus binding sequence (wild type or mutant) was added in increasing amounts to the ELISA plate. The $0.5 \mathrm{~mol} / \mathrm{L} \mathrm{KCl}$ denotes the protein fractions eluted from the DNA affinity column using -350- to -700-bp promoter regions of CAV3. C, F, and G: Immunoblot analysis of protein fractions eluted from the -350 -

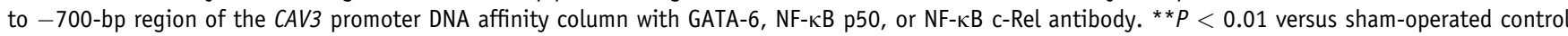
mice. oligo, oligonucleotide.

demonstrated that mutation of the GATA motif in these promoters increased the activity (threefold) compared with that of WT promoters (Figure 6H). Mutation at the GATA motif of $C A V 2$ and $C A V 3$ promoter abolished the repressive effect of GATA-6 (Figure 6H). Cotransfection of WT CAV2 and $C A V 3$ promoters with GATA- 6 cDNA significantly down-regulated the promoters' activity (threefold), whereas cotransfection of mutant $C A V 2$ and $C A V 3$ promoters with GATA-6 cDNA did not alter the promoters' activity (Figure 6H). A representative immunoblot showing the expression levels of ectopically expressed GATA-6 compared with their levels in the control is shown in Figure 6I. GATA-6 protein expression level in BSM cells infected with shRNA specific for GATA-6 was significantly reduced compared with nonspecific (scrambled) shRNA infected cells (Figure 6J). These results provide direct evidence that transcriptional repression of $C A V 2$ and $C A V 3$ genes in human BSM cells is mediated by GATA- 6 .

\section{NF- $\kappa B$ Represses CAV2 and CAV3 Gene Transcription}

The expression levels of CAV2 and CAV3 mRNA (Figure 7A) and protein (Figure 7B) increased significantly in NF- $\kappa \mathrm{B}$ p50 and c-Rel KO murine BSM compared with their levels in WT BSM tissue. The relative intensities of the bands for CAV2 and CAV3 in Figure 7, A and B, were quantified after normalization with glyceraldehyde-3phosphate dehydrogenase (Figure 7, C-F). To examine the effect of endogenous $N F-K B$ gene silencing in vivo in regulating $C A V 2$ and $C A V 3$ promoter activity, these promoters were transfected in murine BSM cells isolated from $\mathrm{NF}-\kappa \mathrm{B}$ p50 and NF- $\kappa \mathrm{B}$ c-Rel KO mice. Luciferase activity driven by human $C A V 2$ and $C A V 3$ promoters was threefold higher in BSM cells from NF- $\kappa$ B p50 and NF- $\kappa$ B c-Rel KO mice compared with the BSM cells from WT mice (Figure 7, G and $\mathrm{H}$ ). Transfection analysis revealed that mutation of the $\mathrm{\kappa B}$ motifs in $C A V 2$ and $C A V 3$ promoters increased the luciferase activity (threefold) compared with that of WT promoters (Figure 7I). Mutation at the $\kappa \mathrm{B}$ motif of the $C A V 2$ and $C A V 3$ promoters abolished the repressive effect of NF- $\kappa \mathrm{B}$ (Figure 7I). Cotransfection of WT promoters with NF- $\kappa \mathrm{B}$ p50 and c-Rel significantly downregulated $C A V 2$ and $C A V 3$ promoter activity (3.2-fold), whereas cotransfection of mutant $C A V 2$ and $C A V 3$ promoters with NF- $\kappa$ B p50 and c-Rel did not have any effect on the promoters' activity (Figure $7 \mathrm{I}$ ). Figure $7 \mathbf{J}$ shows the 
A

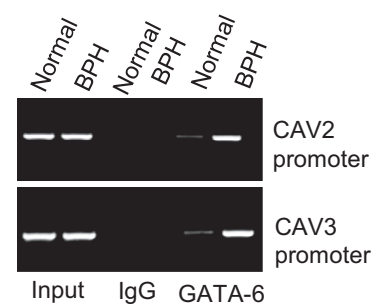

E

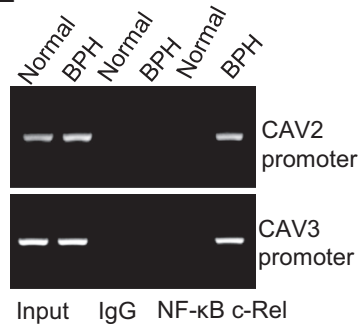

B

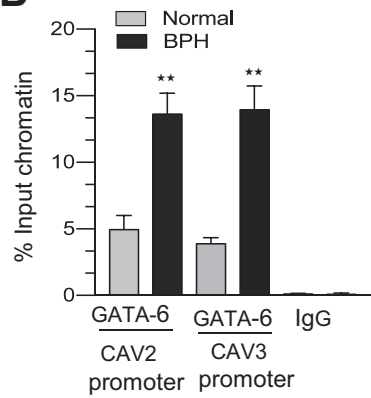

$\mathbf{F}$

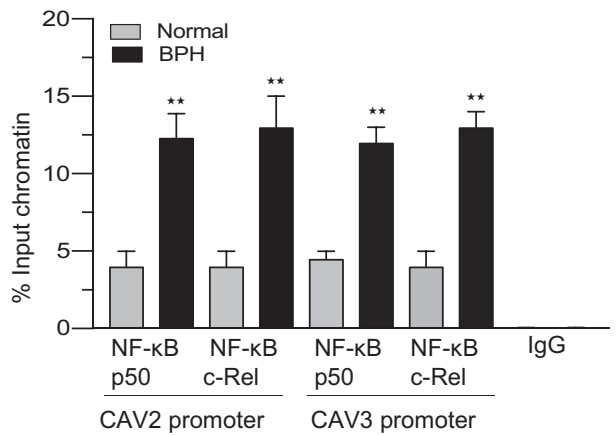

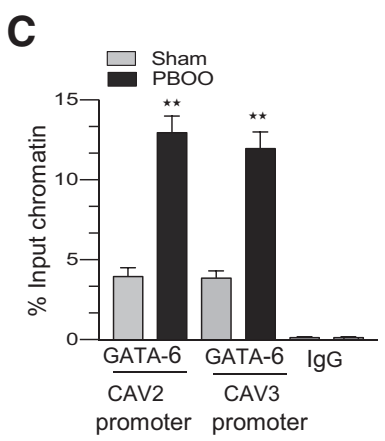

D

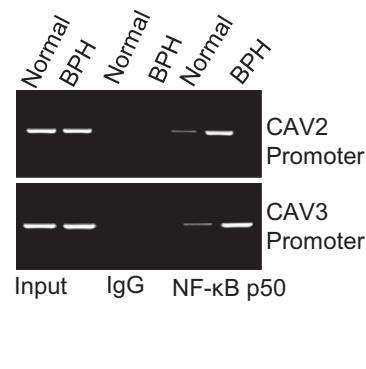

G

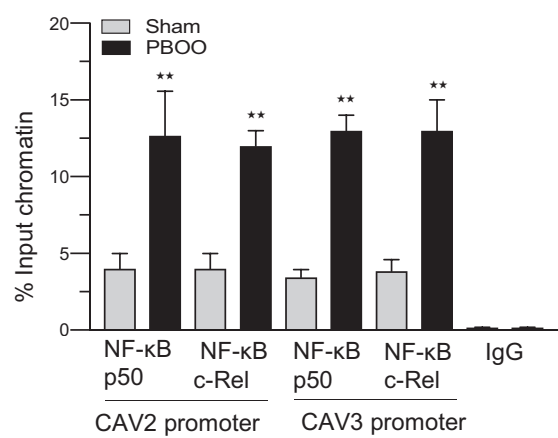

Figure 5 Increased binding of GATA-binding factor 6 (GATA-6) and NF- $\mathrm{B}$ to CAV2 and CAV3 promoters in obstructed bladder smooth muscle (BSM). Chromatin samples prepared from control and benign prostatic hyperplasia (BPH) patients and sham and PBO0 mouse BSM were immunoprecipitated with anti-GATA-6, anti-NF- $\kappa$ B p50, and NF- $\kappa$ B C-Rel antibodies or preimmune rabbit serum. Precipitated fragments were PCR amplified using primers specific for GATA or $\kappa B$ motifs on the human and mouse CAV2 and CAV3 promoters. Quantification of band intensities from agarose gels is presented as percentages of input chromatin. Data are expressed as means \pm SD (B, C, F, and $\mathbf{G}) . n=6$ sham and PB00 mouse BSM (C and $\mathbf{G}) ; n=5$ control and BPH patient tissue (B and F). ${ }^{* *} P<0.01$ versus control.

canonical and the mutant version of the NF- $\kappa \mathrm{B}$ binding site within the $C A V 2$ and $C A V 3$ promoter. Immunoblot analyses demonstrated the absence of p50 and c-Rel protein in BSM tissue from NF- $\kappa \mathrm{B}$ p50 and c-Rel KO mice (Figure 7, K and $\mathrm{L}$ ) and the expression levels of ectopically expressed NF- $\kappa \mathrm{B}$ p50 and c-Rel protein compared with their levels in control cells (Figure 7, M-O). Together, these findings demonstrate that NF- $\mathrm{KB}$ acts as a transcriptional repressor of $C A V 2$ and $C A V 3$ gene transcription in BSM.

\section{Transcriptional Repression of CAV1 Gene by NF- $\kappa B$}

GATA-6 acts as a transcriptional repressor of $C A V 1$ gene expression in PBOO-induced BSM hypertrophy in mice and in men with $\mathrm{BPH} .{ }^{22}$ Herein, it was demonstrated that NF- $\kappa \mathrm{B}$ represses $C A V 2$ and $C A V 3$ gene transcription in BSM. The role of NF- $\mathrm{KB}$ on $C A V I$ gene expression in BSM was next addressed. The expression of CAV1 mRNA (Figure 8A) and protein (Figure $8 \mathrm{~B}$ ) increased significantly in NF- $\kappa \mathrm{B}$ p50 and NF- $\kappa \mathrm{B}$ c-Rel KO murine BSM compared with their levels in WT BSM tissue. The relative intensities of the bands for CAV1 in Figure 8, A and B, were quantified after normalization with GAPDH (Figure 8, C and D). To examine the effect of endogenous $N F-\kappa B$ gene silencing in regulating $C A V 1$ promoter activity, the promoter in murine BSM cells isolated from NF- $\kappa \mathrm{B}$ p50 and NF- $\kappa \mathrm{B}$ c-Rel $\mathrm{KO}$ mice was transfected. Luciferase activity driven by human $C A V 1$ promoter was threefold higher in BSM cells from NF- $\kappa$ B p50 and NF- $\kappa \mathrm{B}$ c-Rel KO mice compared with the BSM cells from WT mice (Figure 8, E and F). Analysis of human $C A V 1$ promoter identified two putative NF- $\kappa$ B binding sites ( -358 and -760 $\mathrm{bp}$ ), and these binding sites are conserved in murine $C A V 1$ promoter at -353 and -878 bp (Figure $8, \mathrm{G}$ and $\mathrm{H}$ ). Transfection analysis of human WT and mutant $C A V I$ promoter in human BSM cells demonstrated that mutation of the $\kappa \mathrm{B}$ motif at -760 bp in the promoter increased the luciferase activity (threefold) compared with that of WT promoter (Figure 8I). Mutation at the $\kappa \mathrm{B}$ motif of the CAV1 promoter abolished the repressive effect of NF-KB (Figure 8I). Cotransfection of WT promoter with NF- $\mathrm{B}$ p50 and c-Rel significantly downregulated CAVI promoter activity (3.1-fold), whereas cotransfection of mutant $C A V 1$ promoter with NF- $\mathrm{BB}$ p50 and NF- $\kappa B$ c-Rel did not have any effect on the promoter activity (Figure 8I). There was an increased binding of NF- $\kappa$ B p50 and NF- $\kappa \mathrm{B}$ c-Rel to $C A V 1$ promoter in BSM from obstructed bladders of $\mathrm{BPH}$ patients and murine $\mathrm{PBOO}$ compared with that in BSM samples of control humans and sham-operated control mice (Figure 8, $\mathrm{J}$ and $\mathrm{K}$ ). The expression of $C A V 1$ gene in BSM from obstructed bladders inversely correlated with NF- $\kappa \mathrm{B}$ p50 and NF- $\kappa \mathrm{B}$ c-Rel binding to the $C A V 1$ promoter at $-760 \mathrm{bp}$ in humans and at $-878 \mathrm{bp}$ in mice. Together, these findings demonstrate that NF- $\kappa \mathrm{B}$ acts as a 
A

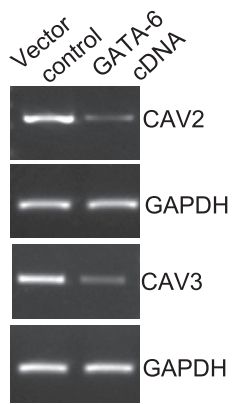

B

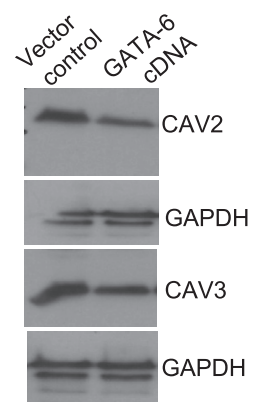

C

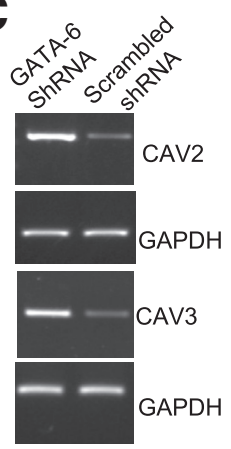

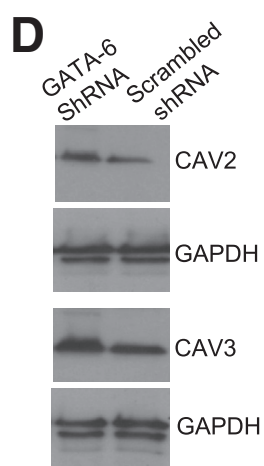

E

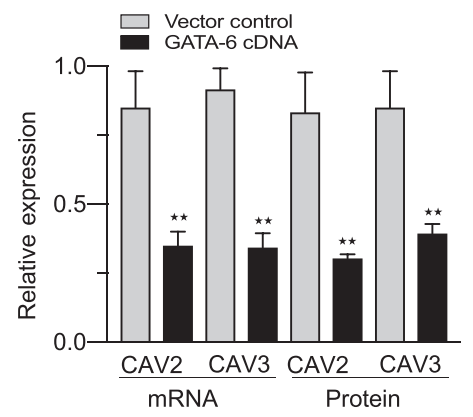

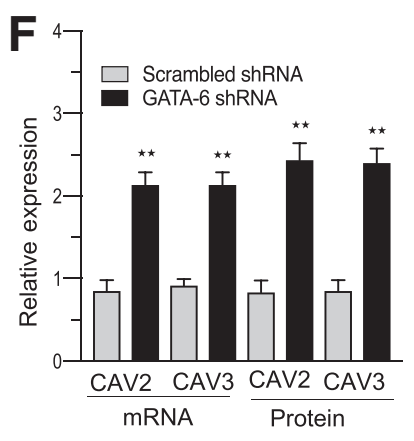

G

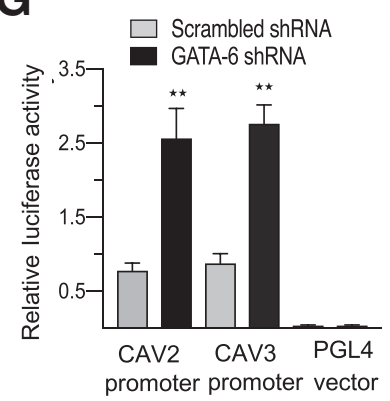

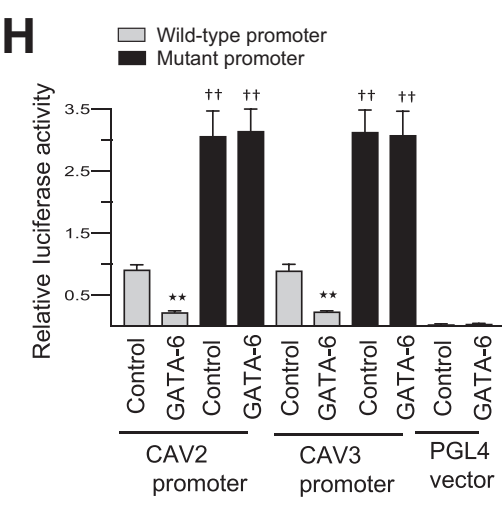

WT CAV2 promoter (GATA motif) 5'-ACAACGTTGATTGGAAGTTT-3' 3'-TGTTGCAACTAACCTTCAAA-5'

Mut CAV2 promoter (GATA motif) 5'-ACAACGTTCTGGGGAAGTTT-3' 3'-TGTTGCAAGACCCCTTCAAA-5

WT CAV3 promoter (GATA motif) 5'-GAGCCCTGATAGTTATTAT-3' 3'-CTCGGGACTATCAATAATA-5

Mut CAV3 promoter (GATA motif) 5'-GAGCCCTCTGGGTTATTAT-3' 3'-CTCGGGAGACCCAATAATA-5'
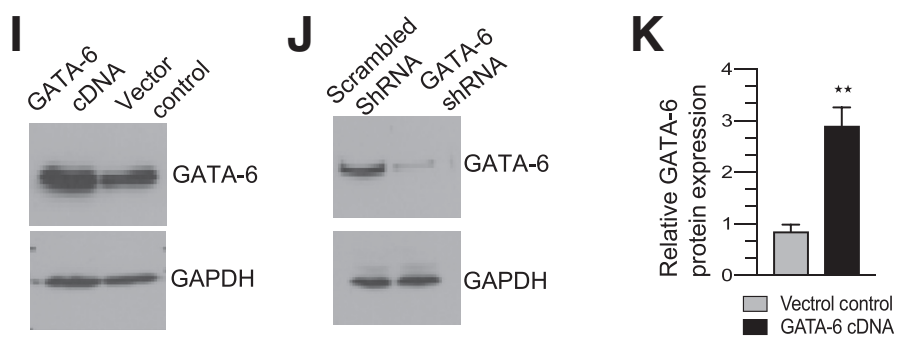

L

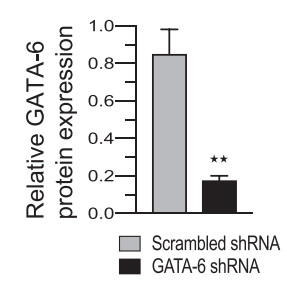

Figure 6 GATA-Binding factor 6 (GATA-6) represses CAV2 and CAV3 gene expression and promoter activity in human primary bladder smooth muscle (BSM) cells. A-D: Human BSM cells were transduced with adenovirus encoding GATA-6, adenoviral harboring cytomegalovirus (Ad-CMV; control), scrambled shRNA (control), and GATA- 6 shRNA individually for 72 hours. A-D: RNA and protein were extracted and subjected to RT-PCR (A and C) and immunoblot analysis (B and D) for CAV2, CAV3, and glyceraldehyde-3-phosphate dehydrogenase (GAPDH). A-F: Data from the experiments for which representative results are shown (A-D) are quantitated (E and F). G: Relative CAV2 and CAV3 promoter reporter luciferase activity in human BSM cells transfected with scrambled and GATA-6 shRNA. Reporter firefly luciferase activities were normalized to Renilla luciferase activity. H: Human BSM cells were cotransfected with human wild-type (WT) or mutant CAV2 and CAV3 promoter reporter luciferase constructs and GATA- 6 cDNA. Mutant nucleotides are shown in boldfaced font. Luciferase activity was measured in each sample after 72 hours and is presented relative to that of Renilla luciferase. I: Representative immunoblot showing the expression levels of ectopically expressed GATA-6 compared with their endogenous levels. J: Immunoblot analysis of total protein from cells transduced with scrambled and GATA- 6 shRNA lentivirus vectors. I and J: GAPDH was probed as a loading control. I-L: Quantification ( $\mathbf{K}$ and $\mathbf{L}$ ) of bands ( $\mathbf{I}$ and $\mathbf{J}$ ) for GATA-6 protein is presented relative to GAPDH. Data are expressed as the means $\pm \mathrm{SD}(\mathbf{E}-\mathbf{H}, \mathbf{K}$, and $\mathbf{L}) . n=4$ experiments $(\mathbf{E}-\mathbf{H}, \mathbf{K}$, and $\mathbf{L}) .{ }^{*} P<0.01$ versus control; ${ }^{\dagger \dagger} P<0.01$ versus wild-type CAV2 and CAV3 promoters.

transcriptional repressor of $C A V 1$ gene transcription in BSM, thus providing important information regarding the molecular mechanism responsible for $C A V I$ down-regulation during BSM remodeling and hypertrophy associated with $\mathrm{BPH}-$ induced lower urinary tract symptoms.

GATA- 6 and NF- $\kappa$ B Binding Levels to GATA and $\kappa B$ Motifs of CAV1, CAV2, and CAV3 Promoters Are Independent of Each Other

GATA-6 gene silencing did not impair the binding of NF- $\kappa \mathrm{B}$ c-Rel and p50 to $C A V 1, C A V 2$, and $C A V 3$ promoters. The binding of NF- $\kappa \mathrm{B}$ p50 and NF- $\kappa \mathrm{B}$ c-Rel to the $C A V 1, C A V 2$, and $C A V 3$ promoters in GATA-6 shRNA-transduced cells was equivalent to that in scrambled shRNA-transduced human BSM cells (Figure 9A). Similarly, the binding of GATA- 6 to the $C A V 1, C A V 2$, and $C A V 3$ promoters did not change in BSM from NF- $\kappa \mathrm{B}$ c-Rel and NF- $\kappa \mathrm{B}$ p50 KO mice compared with their binding in BSM from WT mice (Figure 9B); loss of one transcription factor does not affect the binding of the other transcription factors (Figure 9). These findings suggest that GATA- 6 does not regulate NF- $\kappa$ B or vice versa and that GATA- 6 and NF- $\kappa$ B regulate $C A V$ gene transcription independently in BSM. 

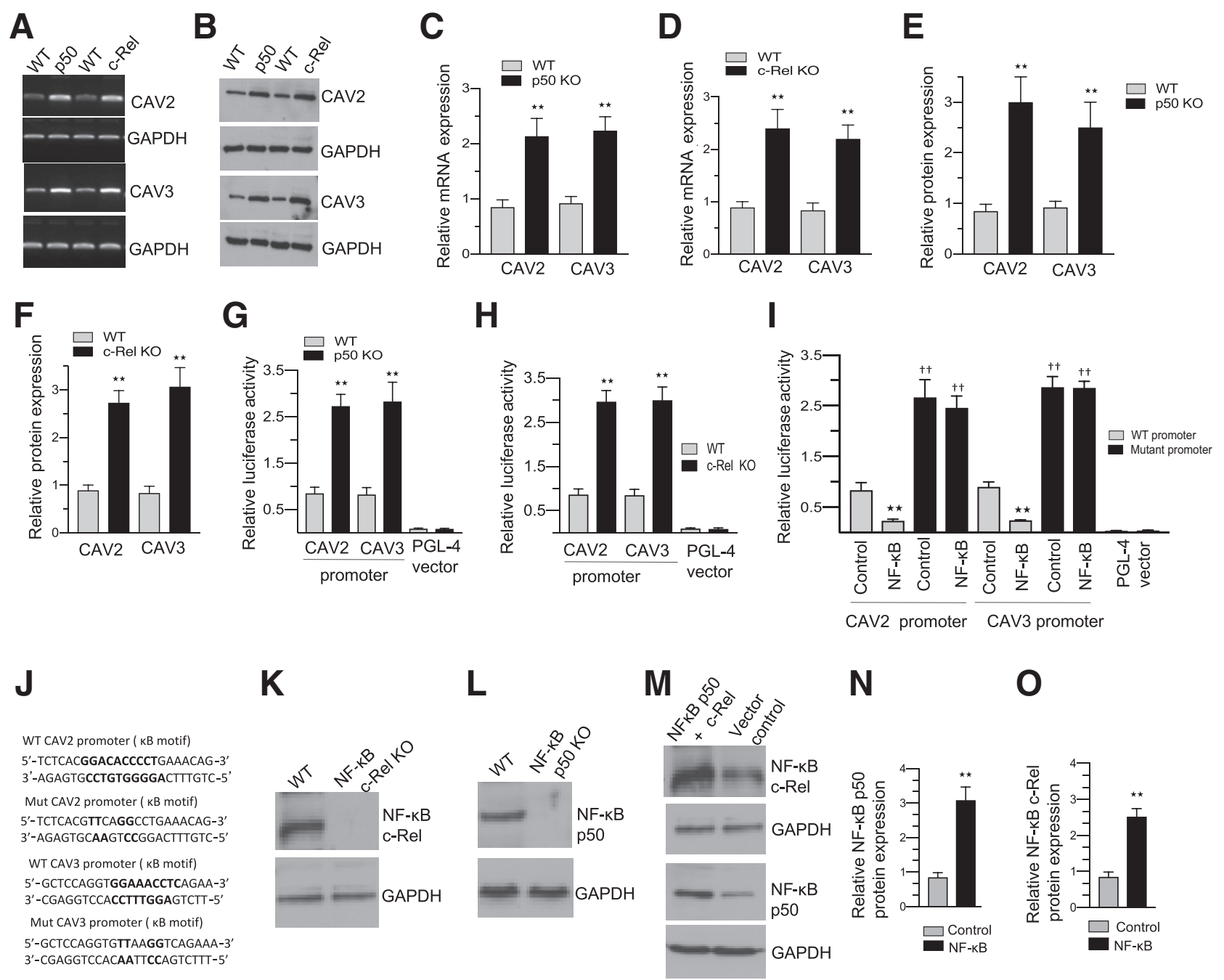

$\mathbf{N}$

Figure 7 NF- $\mathrm{B}$ B silencing up-regulates CAV2 and CAV3 gene expression and promoter activity in bladder smooth muscle (BSM). A and B: RNA and protein samples prepared from BSM of wild-type (WT), NF- $\kappa B$ p50, and NF- $\kappa B$ c-Rel knockout (KO) mice were subjected to RT-PCR (A) and immunoblot (B) analysis for CAV2, CAV3, and glyceraldehyde-3-phosphate dehydrogenase (GAPDH). GAPDH was used as a loading control. A-F: Quantification of band intensities (C-F) from agarose gels (A) and immunoblot (B). G and $\mathbf{H}$ : Relative CAV2 and CAV3 promoter reporter luciferase activity in murine BSM cells from WT, NF- $K B$ p50, and NF- KB C-Rel K0 mice. I and J: Human BSM cells were cotransfected with human WT or mutant (Mut) CAV2 and CAV3 promoter luciferase reporter constructs, NF$\kappa B$ p50, and NF- $\kappa B$ c-Rel cDNA. J: Mutant nucleotides are shown in boldfaced font. Firefly luciferase activity was measured in each sample after 72 hours and is presented relative to that of Renilla luciferase. $\mathbf{K}$ and $\mathbf{L}$ : Immunoblot analysis of total protein from BSM of WT, NF- $\kappa B$ p50, and NF- $K B$ c-Rel K0 mice for NF- $\kappa B$ p50 and NF- $\kappa$ B c-Rel protein and GAPDH. M: Representative immunoblot showing the expression levels of ectopically expressed NF- $\kappa B$ p50 and NF- $\kappa B$ c-Rel compared with their endogenous levels. $\mathbf{M}-\mathbf{0}$ : Bands from immunoblot (M) for NF- $\kappa B$ p50 and NF- $\kappa B$ c-Rel protein were quantitated, and the data are presented relative to GAPDH ( $\mathbf{N}$ and $\mathbf{0})$. Data are expressed as the means \pm SD $(\mathbf{C}-\mathbf{I}, \mathbf{N}$, and $\mathbf{0}) . n=5$ experiments $(\mathbf{C}-\mathbf{F}) ; n=4$ experiments $(\mathbf{G}-\mathbf{I}, \mathbf{N}$, and $\mathbf{0})$. ${ }^{* *} P<0.01$ versus control; ${ }^{\dagger} P<0.01$ versus WT CAV2 and CAV3 promoter reporter luciferase activities.

Small-Molecule Inhibitors of GATA-6 and NF- $\kappa$ B UpRegulate CAV1, CAV2, and CAV3 Gene Expression in Human BSM Cells

It was investigated whether K-7174 and BAY 11-7082, specific inhibitors of GATA and NF- $\kappa \mathrm{B}$, respectively, induce the $C A V 1, C A V 2$, and $C A V 3$ gene expression in human BSM cells. Treatment of human BSM cells with K7174 or BAY 11-7082 compound for 48 hours resulted in the up-regulation of $C A V 1, C A V 2$, and $C A V 3$ mRNA and protein expression relative to the level of vehicle-treated cells (Figure 10). Together, these data demonstrate that small-molecule inhibitors of GATA- 6 and NF- $\kappa \mathrm{B}, \mathrm{K}-7174$ and BAY 11-7082, respectively, induce $C A V 1, C A V 2$, and $C A V 3$ gene expression in human BSM cells; and these results are consistent with our data obtained in this study using genetic strategies.

Small-Molecule Inhibitors of GATA- 6 and NF- $\kappa$ B UpRegulate CAV1, CAV2, and CAV3 Gene Expression in Vivo in Murine BSM

The effect of GATA- 6 and NF- $\kappa$ B inhibitors, K-7174 and BAY 11-7082, respectively, on $C A V 1, C A V 2$, and $C A V 3$ 


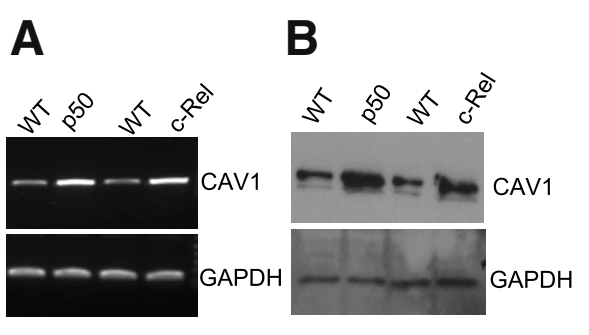

G

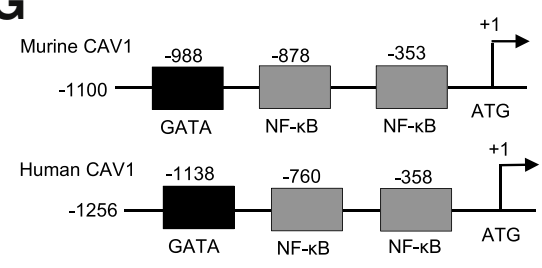

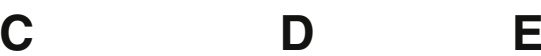

E

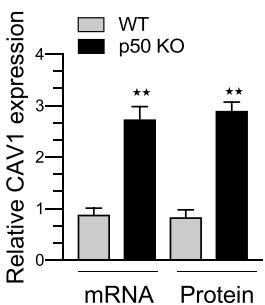

H

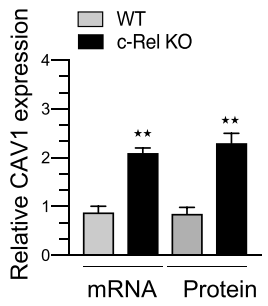

mRNA Protein

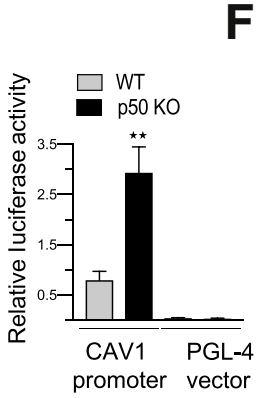

$\mathbf{F}$

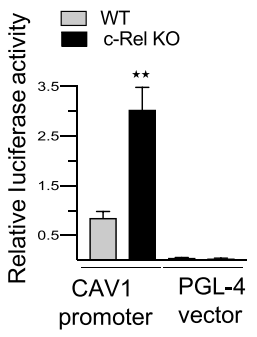

Caveolin-1 promoter sequence

h -1143 5'-TITGGATA ATGAGTTTCCTGATTAATTA CAGCTCAAGA GTAAAATGAC TGATTACTAT T- $3^{\prime}$ m-1011 5'-GAGGCTGGCC AGCTITIGAA ACT GATATIT TAGTTGTTAA CTTAAAAAGA AAAACTACTT -3'

h -783 5'-CATTCTTAT TTCGAAGCGT TTGGGAGACC TTTCAGAAAC GGATGGGAAA TGTTAAATTC-3' m -891 5'-TATTCCTGCGCTTGGATCCTCTATGGCAGAGGATGTAGTTCAGTGGTAGAGTGTTIAATC-3'

h -363 5'-CCCCGGGACG CCTCTCGGTG GTTCAGAGCA GGGAAAATTG TTGCCTCAGG TAAAATAATC-3' m -361 5'-TCTCCCCTGGATGCCTCTCTGTAGGTTIATAGCTGGGAAAACGTTGCCTCGAGTCTAAAA-3'
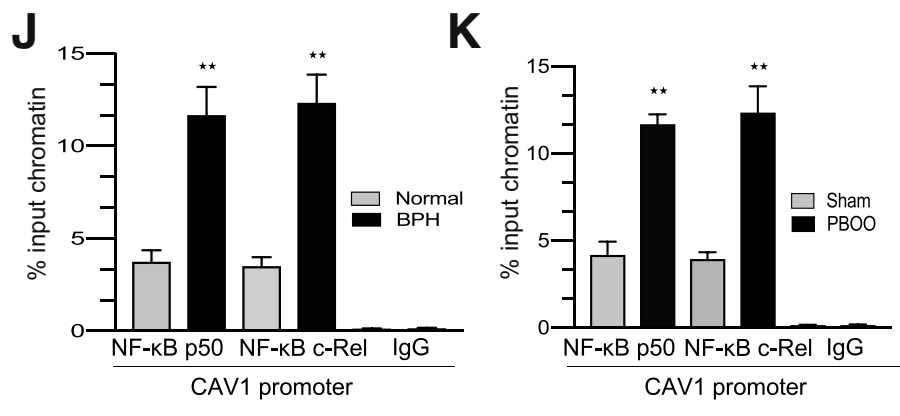

Figure $8 \quad \mathrm{NF}-\mathrm{KB}$ silencing up-regulates CAV1 gene expression and promoter activity in bladder smooth muscle (BSM). A and B: RNA and protein samples prepared from BSM of wild-type (WT), NF- $\kappa B$ p50, and NF- $\mathrm{B}$ C-Rel knockout (K0) mice were subjected to RT-PCR (A) and immunoblot (B) analysis for CAV1 and glyceraldehyde-3-phosphate dehydrogenase (GAPDH). GAPDH was used as a loading control. A-D: Quantification (C and $\mathbf{D})$ of band intensities from agarose

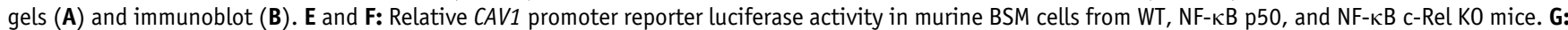
Schematic representation of human and murine CAV1 promoter is shown. Nucleotides are numbered beginning with the translation start site (ATG). The direction of transcription is marked with an arrow. The putative binding site for GATA-binding factor 6 (GATA- 6 ) and NF- $\kappa B$ on human and murine CAV1 promoter is shown. H: Sequence homology between the human and murine CAV1 promoter. Sequence identity between the human and mouse CAV1 promoter is significantly lower (these sequences are blue) as the distance from the ATG start site is increased. The sequences that are boldfaced and underlined in mouse $(\mathrm{m})$ and human (h) CAV1 promoter confirm to consensus binding site of GATA-6 (GATA motif) and NF- $\mathrm{KB}$ (GGRNNYYCC is the consensus sequence, and it is alias $\kappa B$ site, where $R$ is a purine, $Y$ is a pyrimidine, and $N$ is any nucleotide). I: Human BSM cells were cotransfected with human WT or mutant (Mut) CAV1 promoter luciferase reporter constructs, NF- $\mathrm{B}$ p 50 , and NF- $\mathrm{B}$ c-Rel cDNA. Mutant nucleotides are shown in boldfaced font. Firefly luciferase activity was measured in each sample after 72 hours and is presented relative to that of Renilla luciferase. $\mathbf{J}$ and $\mathbf{K}$ : Chromatin samples from control and benign prostatic hyperplasia

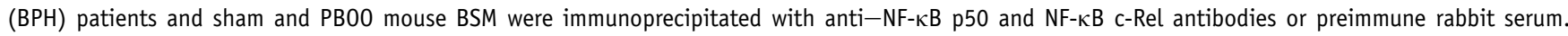
Precipitated fragments were PCR amplified using primers specific for $\kappa B$ motifs on the human and mouse CAV1 promoter. Quantification of band intensities from agarose gels is presented as percentage of input chromatin. Data are expressed as means \pm SD $(\mathbf{C}-\mathbf{F}$ and $\mathbf{I}-\mathbf{K}) . n=5$ experiments $(\mathbf{C}$ and $\mathbf{D}) ; n=4$ experiments (E, F and $\mathbf{I}) ; n=5$ control and BPH patients $(\mathbf{J}) ; n=6$ sham and PB00 mouse BSM (K). ${ }^{* *} P<0.01$ versus control; ${ }^{\dagger \dagger} P<0.01$ versus WT CAV2 and CAV3 promoter reporter luciferase activities.

gene expression was determined in vivo in murine BSM. $C A V 1, C A V 2$, and $C A V 3 \mathrm{mRNA}$ and protein expression was measured in BSM from K-7174- or BAY 11-7082-treated mice. The expression of $C A V 1, C A V 2$, and $C A V 3$ mRNA and protein increased in response to K-7174 and BAY 117082 treatment relative to that in vehicle-treated murine BSM (Figure 11). Together, these results are consistent with the findings obtained in this study using genetic strategies in human BSM cells.

\section{Discussion}

The molecular changes identified in the current study with 2week PBOO mice are consistent with data shown for decompensated bladder. ${ }^{25}$ An earlier study has demonstrated that these PBOO mice with decompensated bladder show decline in pressure in response to stimulation with electrical field or $\mathrm{KCl}$ compared with sham-operated control, as shown by the in vitro organ physiology. ${ }^{25,38,39}$ The evidence 

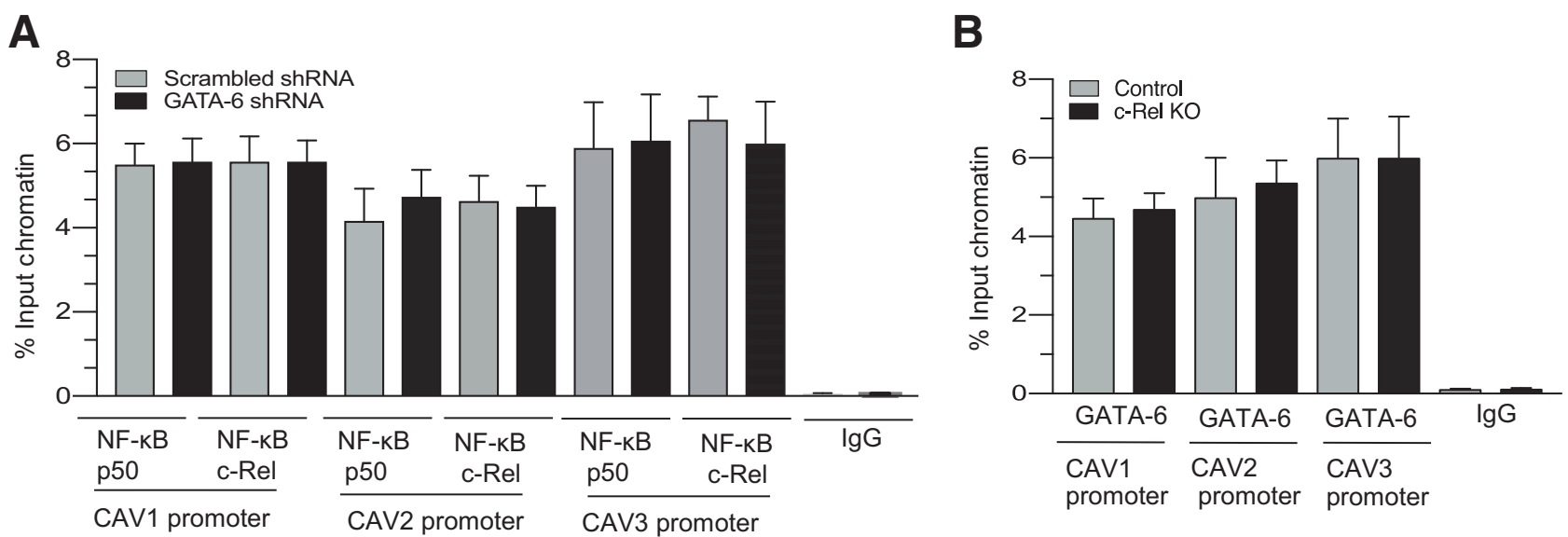

Figure 9 Recruitment levels of GATA-binding factor 6 (GATA- 6$)$ and NF- $\kappa B$ to GATA and $\kappa B$ motifs of CAV promoters are independent of each other. Chromatin immunoprecipitation (ChIP) analysis of CAV1, CAV2, and CAV3 promoters in scrambled (control) and GATA-6 shRNA knockdown bladder smooth muscle (BSM) cells with NF- $\kappa B$ and c-Rel antibodies and in wild-type and c-Rel knockout (KO) murine BSM tissue with GATA- 6 antibody. GATA and $\kappa B$ motifs in the CAV1, CAV2, and CAV3 were amplified by PCR. Preimmune serum (IgG) was used as a negative control in both ChIP experiments. Data are expressed as the means \pm SD. $n=4$ experiments (A and $\mathbf{B})$.

provided is as follows: i) mice subjected to PBOO displayed an increase in the bladder/body weight ratio; ii) loss of RYR2, RYR3, and ATPase expression, as shown by the microarray; and iii) loss of muscle markers, SM22 and smooth myosin heavy chain, and CAV gene expression and increased expression of the proliferative gene, vimentin, in 2-week obstructed murine bladder. Masson's trichrome-stained tissue sections displayed increased collagen deposition between muscle bundles. Earlier studies have demonstrated that after PBOO, there is a marked phase of decompensation that is characterized by increased bladder weight, loss of response to field stimulation, and loss of response to direct agonist stimulation. Contractile responses from decompensated bladders from obstructed mice displayed decreased force generation in response to carbachol and $\mathrm{KCl}$ stimulation. ${ }^{40}$ Previous data have shown a major loss in the expression of SERCA2 and RYR with bladder decompensation; loss of SERCA2 (sarco/endoplasmic reticulum $\mathrm{Ca}^{2+}$-ATPase) correlated strongly with a loss of ATPase expression. ${ }^{41-43}$ In a rabbit PBOO model, there was a correlation between the loss of contractile force and a loss of ATPase and RYR2 expression. ${ }^{35,42}$ Similar to the rabbit model, these mice showed loss of RYR2, RYR3, and ATPase expression. In this study, the functional consequences of PBOO were inferred from our previous studies. ${ }^{25,38,39}$ Cystometry or force measurements were not performed with the PBOO mice bladders to assess the voiding behavior or the contraction, which is a potential limitation in this study. The consistency of the functional changes in the murine model of PBOO has been shown extensively. ${ }^{22,25,38,39}$ However, assessing the murine bladder function in the present study along with molecular and biochemical measurements would have allowed classifying the bladders unequivocally as compensated or decompensated.

The present study further details the mechanism of transcriptional repression of $C A V 1, C A V 2$, and $C A V 3$ genes that occurs in BSM in the context of obstructive bladder disease. This study demonstrates, for the first time, that GATA- 6 and $N F-\kappa B$ repress $C A V$ gene transcription by binding to GATA and $\kappa \mathrm{B}$ motifs, respectively, in the CAV gene promoter in human and murine BSM. Furthermore, these results demonstrate the inverse relationship between the CAV gene expression levels and the levels of GATA- 6 and NF- $\kappa$; silencing NF- $\kappa$ B and GATA-6 gene expression upregulates CAV gene expression in BSM tissue and cells, whereas overexpression of GATA-6 protein sustains the transcriptional repression of these genes in BSM cells. Pharmacologic inhibition of GATA- 6 and NF- $\kappa$ B in murine bladder in vivo and in cultured human BSM cells increased $C A V 1, C A V 2$, and $C A V 3$ gene expression. Results from experiments using cultured BSM cells and intact BSM tissue from mice and human patients suggest that GATA- 6 and $\mathrm{NF}-\kappa \mathrm{B}$ act as transcriptional repressors; and these transcription factors suppress CAV gene expression in obstructed BSM, likely because of their increased binding to GATA and $\kappa \mathrm{B}$ motifs, respectively, in the CAV gene promoters in these tissues. Collectively, these findings establish a new mechanism by which CAV gene expression is repressed in hypertrophied BSM in obstructive bladder disease.

Fang et $\mathrm{al}^{44}$ recently reported that silencing the GATA6 gene inhibited ovalbumin-induced airway inflammation and remodeling via CAV1, at least in part through NF- $\mathrm{BB}$ in a murine model of chronic asthma. GATA-6 knockdown markedly reduced the NF- $\mathrm{B}$ p 65 phosphorylation, increased the CAV1 protein level, and attenuated the ovalbumin-induced airway inflammation and remodeling; however, GATA-6 gene silencing did not affect the expression level of NF- $\kappa \mathrm{B} \mathrm{p} 65 .{ }^{44}$ Contrarily, in this study, GATA- 6 gene silencing did not impair the binding

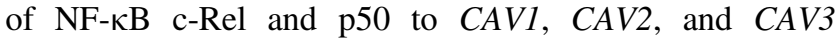
promoters. K-7174, a GATA-specific inhibitor that acts 

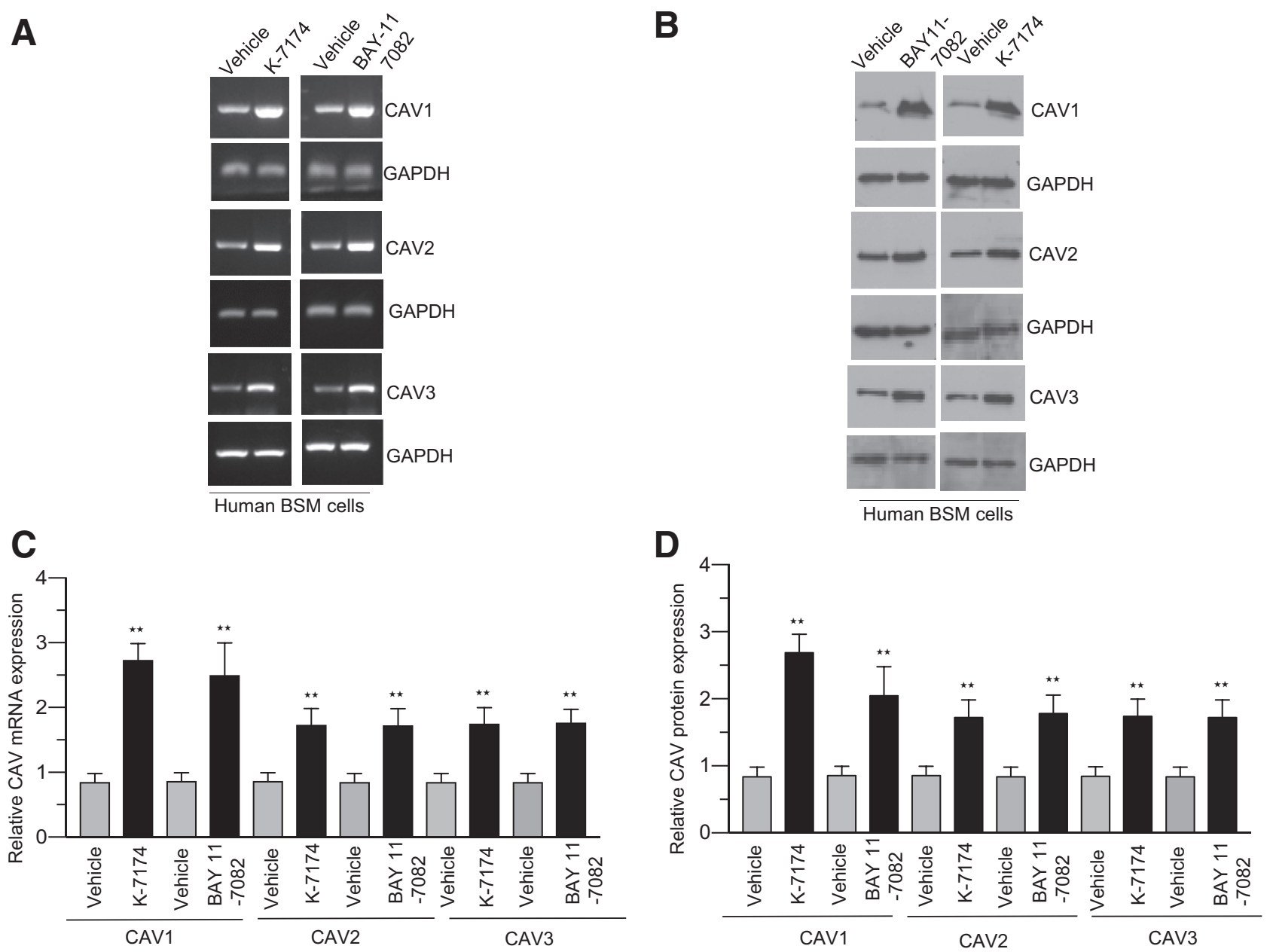

Figure 10 Small-molecule inhibitor of GATA and NF-KB up-regulates CAV1, CAV2, and CAV3 gene expression in human primary bladder smooth muscle (BSM) cells. A and B: Human BSM cells were treated with a GATA-specific pharmacologic inhibitor, K-7174 (5 $\mu$ mol/L), or an NF- $\mathrm{BB}-\mathrm{specific}$ pharmacologic inhibitor, BAY 11-7082 (10 $\mu \mathrm{mol} / \mathrm{L})$, for 48 hours. RNA and protein were extracted and subjected to RT-PCR (A) and immunoblot (B) analysis for CAV1, CAV2, CAV3, and glyceraldehyde-3-phosphate dehydrogenase (GAPDH). C and D: Data are quantitated. Data are expressed as means \pm SD. $n=4$ independent experiments $(\mathbf{C}$ and $\mathbf{D}) .{ }^{* *} P<0.01$ versus vehicle-treated BSM cells.

through a mechanism independent of NF- $\mathrm{B}$ activity, inhibits the binding activity of GATA family transcription factors. ${ }^{33}$ Earlier studies have shown that the smallmolecule inhibitor of NF- $\kappa$ B, BAY 11-7082, inhibited $\mathrm{NF}-\kappa \mathrm{B}$ activity and induced apoptosis in uveal melanoma cells and in human fibroblast-like synovial cells in rheumatoid arthritis. ${ }^{32,45}$ These data also demonstrate, for the first time, that GATA and NF- $\kappa$ B inhibitors, administered via i.p. injection to mice, or to human primary BSM cells in culture, up-regulate CAV1, CAV2, and $C A V 3$ gene expression; and these results are consistent with the data obtained using genetic strategies in this study.

Previous studies have identified two sterol regulatory element-like sequences and the sterol regulatory element-binding protein-1 that regulate $C A V I$ gene transcription, and these elements inhibits CAVI gene transcription in response to cholesterol efflux. ${ }^{46}$ Additional studies have shown that a complex of specificity protein 1
(SP-1), E2F/dimerization partner 1 (DP-1), and p53 is involved in the regulation of $C A V l$ gene transcription in response to cholesterol homeostasis in human skin fibroblasts. ${ }^{47}$ Forkhead box class $\mathrm{O}$ transcription factors directly control $C A V 1$ gene expression. ${ }^{48}$ Hypoxia-inducible factor up-regulates CAV1 expression. ${ }^{49}$ Earlier studies have shown that the transcription factor, myogenin, up-regulates the $C A V 3$ gene transcription during skeletal myogenesis. ${ }^{50}$ Nitrosylation of myogenin led to a reduced transcriptional activity of this protein, which was responsible for the loss of $C A V 3$ transcription in skeletal muscle. ${ }^{51} \mathrm{Zhu}$ et al ${ }^{52}$ reported recently that overexpression of myocardin family coactivators megakaryoblastic leukemia 1 (MKL1)/myocardinrelated transcription factor A (MRTF-A) activated $C A V 2$ and $C A V 3$ promoter reporter activity in human coronary artery SMCs. Adenoviral transduction of rat BSM cells with MRTF-A or myocardin increased mRNA and protein levels of CAV genes and cavins. ${ }^{52}$ However, Zhu et $\mathrm{al}^{52}$ did not attempt to map the binding sites in the respective promoter 


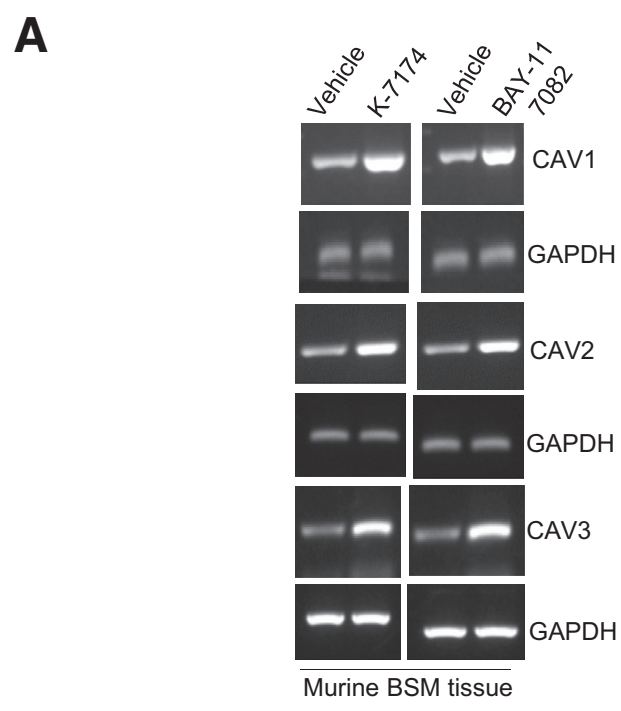

C

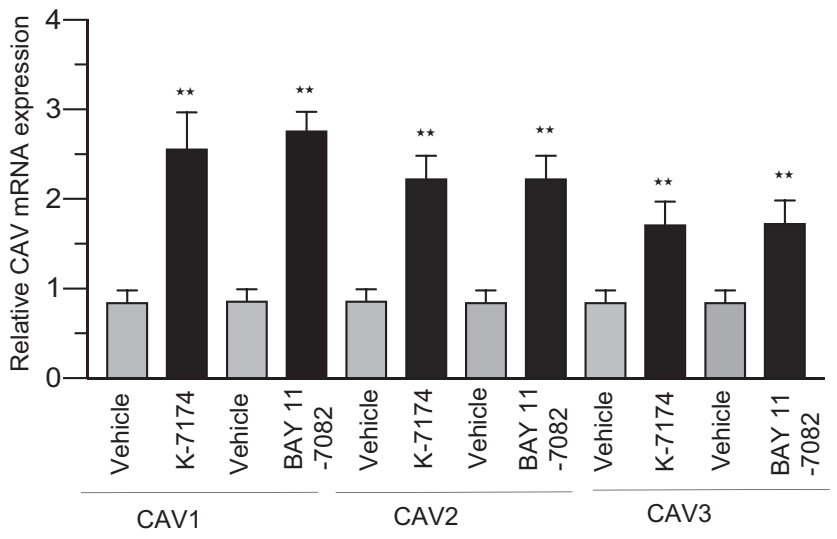

B

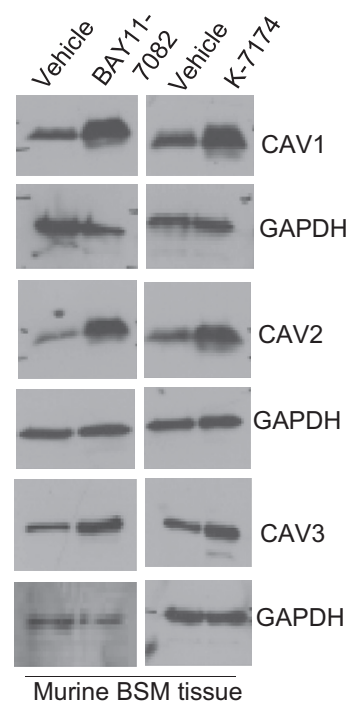

D

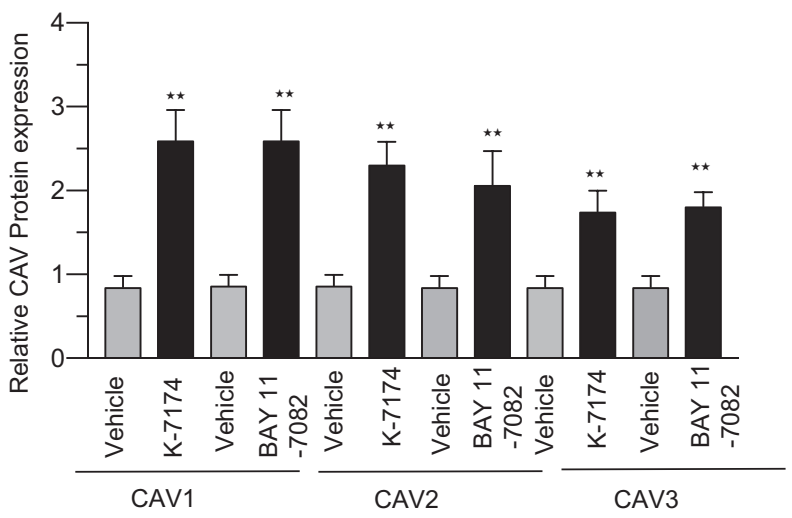

Figure 11 Small-molecule inhibitor of GATA and NF- $K B$ up-regulates CAV1, CAV2, and CAV3 gene expression in murine bladder smooth muscle (BSM) in vivo. A and B: Mice were administrated intraperitoneally with $\mathrm{K}-7174(30 \mathrm{mg} / \mathrm{kg}), \mathrm{BAY} 11-7082(30 \mathrm{mg} / \mathrm{kg})$, or vehicle (dimethyl sulfoxide) once a day for 9 consecutive days. RNA and protein were extracted from bladder tissues and subjected to RT-PCR (A) and immunoblot (B) analysis for determining CAV1, CAV2, CAV3, and glyceraldehyde-3-phosphate dehydrogenase (GAPDH) expression. $\mathbf{C}$ and $\mathbf{D}$ : Data from the experiments for which representative results are shown for RNA and protein are quantitated. Data are expressed as means \pm SD (C and $\mathbf{D}) . n=6$ vehicle, K-7174, and BAY11-7082 (C and $\mathbf{D}) .{ }^{* *} P<0.01$ versus vehicle.

regions to understand how GATA-6 affects CAV and cavin expression. We demonstrate that GATA-6 decreases CAV2 and $C A V 3$ gene expression via the GATA motif in the promoters and that a proximal GATA motif adjacent to the $\kappa \mathrm{B}$ motif is required for $C A V 2$ and $C A V 3$ gene repression. These studies are required because they eliminate the possibility that an abundance of one transcription factor influences transcription indirectly (eg, by increasing the expression of the other transcription factor). This study also provides the novel finding that NF- $\kappa \mathrm{B}$ down-regulates $C A V 1, C A V 2$, and $C A V 3$ gene expression and acts as a transcriptional repressor of these genes. A significant finding of the study is the involvement of GATA-6 and NF$\kappa \mathrm{B}$ in transcriptional regulation of $C A V 1, C A V 2$, and $C A V 3$ gene expression in pathologic smooth muscle from dysfunctional bladders, relating the changes in the molecular regulation of $C A V$ to organ dysfunction.

The vertebrate GATA motif is a DNA sequence motif that conforms to the consensus WGATAR (where W is A or
$\mathrm{T}$ and $\mathrm{R}$ is $\mathrm{A}$ or $\mathrm{G})$. These motifs were described initially in the promoters of erythroid cell globin genes, ${ }^{53-58}$ and similar GATA motifs with assigned functional significance that conforms to this consensus sequence have been described in the promoters of various genes involved in the proliferation and differentiation of cardiac cells and SMCs. ${ }^{59-65}$ GATA-6 regulates the expression of various signaling and contractile proteins in cardiac and smooth muscles, ${ }^{22,61,66-69}$ and GATA-6 gene deletion leads to defects in embryonic development and lethality. ${ }^{70}$ Activation of GATA-6 is strongly associated with pathophysiology of cardiac and smooth muscle hypertrophy. ${ }^{22,71-73}$ This study shows, for the first time, that GATA-6 represses CAV2 and $C A V 3$ gene expression by binding to the GATA sequence in the promoter and decreases these gene mRNA and protein expression levels in BSM. The NF- $\kappa \mathrm{B}$ family of proteins controls various processes in the cardiovascular system, including differentiation, proliferation, inflammation, and cell survival. ${ }^{74-76} \mathrm{NF}-\mathrm{\kappa B}$ also supports cell proliferation 
through transcriptional activation of inhibitors of apoptosis. $^{76} \mathrm{NF}-\kappa \mathrm{B}$ activates $\mathrm{CPI}-17$ (protein kinase $\mathrm{C}$-potentiated inhibitory protein of $17 \mathrm{kDa}$ ) transcription and protein kinase $\mathrm{C}-$ mediated signaling. $\mathrm{NF}-\kappa \mathrm{B}$ activation is associated with obstruction-induced BSM remodeling in patients with BPH. ${ }^{69}$

There is a growing interest in caveolae microdomains given their role in the sequestration and regulation of signaling molecules. ${ }^{3}$ Because caveolae microdomains are known to interact with several ion channels and exchangers in cardiomyocytes, these microdomains may provide a platform for interactions between the sarcoplasmic reticulum and plasmalemmal ion channels in smooth muscle. ${ }^{77,78}$ In addition, Rho-kinase in arterial smooth muscle requires caveolae for the membrane depolarization-induced contraction. $^{79}$ CAV1 KO mice displayed severe pulmonary hypertension, cardiomyopathy, and impaired smooth muscle contraction. ${ }^{14,80}$ Caveolae appear to constitute an important signaling domain that has a role in regulation of smooth muscle tone, ${ }^{81}$ proliferation, ${ }^{77,82}$ and contraction. ${ }^{83}$ Caveolae facilitate muscarinic receptor-mediated intracellular $\mathrm{Ca}^{2+}$ mobilization, which leads to airway smooth muscle contraction by acetylcholine. ${ }^{84}$ CAV1 inhibits myocyte proliferation via its CAV1 scaffolding domain that binds to epidermal growth factor, platelet-derived growth factor receptors, Src kinase, and epidermal growth factor receptor $^{85,86}$ and thereby maintains the SMC quiescent phenotype. Caveolae stimulate transforming growth factor$\beta 1$ signaling in human BSM cells and ureteral SMCs. ${ }^{12,87}$

CAV1 regulates the airway SMC phenotype and contractile protein expression. ${ }^{88}$ Caveolae and caveolin-1 play a significant role in p42/p44 mitogen-activated protein kinase activation and smooth muscle proliferation in human airways. $^{82}$ CAV1 regulates contractility in differentiated vascular smooth muscle. ${ }^{89} \mathrm{CAV} 3$ regulates a switch between the proliferative and contractile phenotype in vascular SMCs. ${ }^{19}$ In a rat animal model of PBOO, there is a downregulation of smooth muscle myosin heavy chain expression that is associated with decreased BSM contractility. ${ }^{90}$ Mice with SMC-specific knockout of myocardin displayed severe urogenital phenotypes, including the thinning of the muscle layer in the bladder ${ }^{91}$; similar effects occur with deletion of either $C A V 1^{14,17,92,93}$ or the cavin-1 ${ }^{93}$ gene. These findings have implications in several other pathophysiological conditions, including cardiac hypertrophy and fibrosis, and these pathologic features include a loss of CAVl gene expression. ${ }^{80}$

In summary, the present study demonstrates, for the first time, that GATA- 6 and NF- $\kappa \mathrm{B}$ are transcriptional repressors of human $C A V 1, C A V 2$, and $C A V 3$ genes in BSM. These findings establish a new mechanism of CAV gene regulation in which the GATA and $\kappa \mathrm{B}$ motifs on the CAV promoters mediate their cognate gene expression through GATA-6 and $\mathrm{NF}-\kappa \mathrm{B}$ recruitment to the promoters in BSM. The data presented in the current study should facilitate further investigation into mechanisms mediating the loss of $\mathrm{CAV}$ gene expression during obstruction-induced BSM remodeling and hypertrophy in mice and humans. Underactive bladder is a common lower urinary tract symptom, characterized by impairment of bladder emptying due to the inability of the bladder to contract effectively in obstructive bladder disease in men. ${ }^{94}$ There are no effective pharmacologic agents to improve detrusor contractility in underactive bladder. Earlier studies have reported the use of parasympathomimetic agents, like muscarinic receptor agonists or anticholinesterases, to augment bladder contractility or $\alpha$-adrenoceptor antagonists to reduce bladder outlet resistance. ${ }^{95}$ However, the use of cholinergic agonist or the cholinesterase inhibitor did not significantly improve contraction in patients with impaired detrusor contractility. ${ }^{95}$ Taken together, these findings emphasize the need to identify novel therapeutic targets for pharmacologic management of underactive bladder. In this study, administration of small-molecule inhibitors of NF- $\kappa$ B and GATA6 resulted in increased $\mathrm{CAV}$ gene expression in murine BSM tissue in vivo and in human BSM cells. These results suggest that GATA- 6 and NF- $\kappa \mathrm{B}$ may be a novel target to mitigate detrusor underactivity in men with $\mathrm{BPH}$-induced bladder dysfunction.

\section{Acknowledgments}

We thank Dr. Hsiou-Chi Liou (Weill Medical College of Cornell University, New York, NY) for kindly providing murine NF- $\kappa \mathrm{B}$ c-Rel knockout mice; and Dr. Christopher Hunter (School of Veterinary Medicine, University of Pennsylvania, Philadelphia, PA) for providing the NF- $\kappa \mathrm{B}$ p50 breeding colony.

\section{Supplemental Data}

Supplemental material for this article can be found at https://doi.org/10.1016/j.ajpath.2018.12.013.

\section{References}

1. Gabella G: Quantitative morphological study of smooth muscle cells of the guinea-pig taenia coli. Cell Tissue Res 1976, 170:161-186

2. Razani B, Woodman SE, Lisanti MP: Caveolae: from cell biology to animal physiology. Pharmacol Rev 2002, 54:431-467

3. Galbiati F, Razani B, Lisanti MP: Emerging themes in lipid rafts and caveolae. Cell 2001, 106:403-411

4. Fielding CJ, Fielding PE: Relationship between cholesterol trafficking and signaling in rafts and caveolae. Biochim Biophys Acta 2003 , 1610:219-228

5. Cohen AW, Hnasko R, Schubert W, Lisanti MP: Role of caveolae and caveolins in health and disease. Physiol Rev 2004, 84: $1341-1379$

6. Sullivan MP, Cristofaro V, Radisavljevic ZM, Yalla SV: Regional distribution and molecular interaction of caveolins in bladder smooth muscle. BJU Int 2012, 110:E1163-E1172

7. Bastiani M, Liu L, Hill MM, Jedrychowski MP, Nixon SJ, Lo HP, Abankwa D, Luetterforst R, Fernandez-Rojo M, Breen MR, Gygi SP Vinten J, Walser PJ, North KN, Hancock JF, Pilch PF, Parton RG: 
MURC/cavin-4 and cavin family members form tissue-specific caveolar complexes. J Cell Biol 2009, 185:1259-1273

8. Hill MM, Bastiani M, Luetterforst R, Kirkham M, Kirkham A, Nixon SJ, Walser P, Abankwa D, Oorschot VM, Martin S, Hancock JF, Parton RG: PTRF-cavin, a conserved cytoplasmic protein required for caveola formation and function. Cell 2008, 132: $113-124$

9. Liu P, Ying Y, Ko YG, Anderson RG: Localization of plateletderived growth factor-stimulated phosphorylation cascade to caveolae. J Biol Chem 1996, 271:10299-10303

10. Couet J, Li S, Okamoto T, Ikezu T, Lisanti MP: Identification of peptide and protein ligands for the caveolin-scaffolding domain: implications for the interaction of caveolin with caveolae-associated proteins. J Biol Chem 1997, 272:6525-6533

11. Patel HH, Zhang S, Murray F, Suda RY, Head BP, Yokoyama U, Swaney JS, Niesman IR, Schermuly RT, Pullamsetti SS, Thistlethwaite PA, Miyanohara A, Farquhar MG, Yuan JX, Insel PA: Increased smooth muscle cell expression of caveolin-1 and caveolae contribute to the pathophysiology of idiopathic pulmonary arterial hypertension. FASEB J 2007, 21:2970-2979

12. Stehr M, Adam RM, Khoury J, Zhuang L, Solomon KR, Peters CA, Freeman MR: Platelet derived growth factor-BB is a potent mitogen for rat ureteral and human bladder smooth muscle cells: dependence on lipid rafts for cell signaling. J Urol 2003, 169:1165-1170

13. Campostrini G, Bonzanni M, Lissoni A, Bazzini C, Milanesi R, Vezzoli E, Francolini M, Baruscotti M, Bucchi A, Rivolta I, Fantini M, Severi S, Cappato R, Crotti L, J Schwartz P, DiFrancesco D, Barbuti A: The expression of the rare caveolin-3 variant $\mathrm{T} 78 \mathrm{M}$ alters cardiac ion channels function and membrane excitability. Cardiovasc Res 2017, 113:1256-1265

14. Woodman SE, Cheung MW, Tarr M, North AC, Schubert W, Lagaud G, Marks CB, Russell RG, Hassan GS, Factor SM, Christ GJ, Lisanti MP: Urogenital alterations in aged male caveolin-1 knockout mice. J Urol 2004, 171:950-957

15. Cao G, Yang G, Timme TL, Saika T, Truong LD, Satoh T, Goltsov A, Park SH, Men T, Kusaka N, Tian W, Ren C, Wang H, Kadmon D, Cai WW, Chinault AC, Boone TB, Bradley A, Thompson TC: Disruption of the caveolin-1 gene impairs renal calcium reabsorption and leads to hypercalciuria and urolithiasis. Am J Pathol 2003, 162:1241-1248

16. Keshavarz M, Schwarz H, Hartmann P, Wiegand S, Skill M, Althaus M, Kummer W, Krasteva-Christ G: Caveolin-1: functional insights into its role in muscarine- and serotonin-induced smooth muscle constriction in murine airways. Front Physiol 2017, 8:295

17. Lai HH, Boone TB, Yang G, Smith CP, Kiss S, Thompson TC, Somogyi GT: Loss of caveolin-1 expression is associated with disruption of muscarinic cholinergic activities in the urinary bladder. Neurochem Int 2004, 45:1185-1193

18. Ackers-Johnson M, Talasila A, Sage AP, Long X, Bot I, Morrell NW, Bennett MR, Miano JM, Sinha S: Myocardin regulates vascular smooth muscle cell inflammatory activation and disease. Arterioscler Thromb Vasc Biol 2015, 35:817-828

19. Gutierrez-Pajares JL, Iturrieta J, Dulam V, Wang Y, Pavlides S, Malacari G, Lisanti MP, Frank PG: Caveolin-3 promotes a vascular smooth muscle contractile phenotype. Front Cardiovasc Med 2015, 2:27

20. Cristofaro V, Peters CA, Yalla SV, Sullivan MP: Smooth muscle caveolae differentially regulate specific agonist induced bladder contractions. Neurourol Urodyn 2007, 26:71-80

21. Polyak E, Boopathi E, Mohanan S, Deng M, Zderic SA, Wein AJ, Chacko S: Alterations in caveolin expression and ultrastructure after bladder smooth muscle hypertrophy. J Urol 2009, 182: 2497-2503

22. Boopathi E, Gomes CM, Goldfarb R, John M, Srinivasan VG, Alanzi J, Malkowicz SB, Kathuria H, Zderic SA, Wein AJ, Chacko S: Transcriptional repression of caveolin-1 (CAV1) gene expression by GATA-6 in bladder smooth muscle hypertrophy in mice and human beings. Am J Pathol 2011, 178:2236-2251
23. Lowalekar SK, Cristofaro V, Radisavljevic ZM, Yalla SV, Sullivan MP: Loss of bladder smooth muscle caveolae in the aging bladder. Neurourol Urodyn 2012, 31:586-592

24. Committee for the Update of the Guide for the Care and Use of Laboratory Animals; National Research Council: Guide for the Care and Use of Laboratory Animals: Eighth Edition. Washington, DC, National Academies Press, 2011

25. Austin JC, Chacko SK, DiSanto M, Canning DA, Zderic SA: A male murine model of partial bladder outlet obstruction reveals changes in detrusor morphology, contractility and myosin isoform expression. $\mathrm{J}$ Urol 2004, 172:1524-1528

26. Chang S, Gomes CM, Hypolite JA, Marx J, Alanzi J, Zderic SA, Malkowicz B, Wein AJ, Chacko S: Detrusor overactivity is associated with downregulation of large-conductance calcium- and voltageactivated potassium channel protein. Am J Physiol Renal Physiol 2010, 298:F1416-F1423

27. Masternak K, Muhlethaler-Mottet A, Villard J, Zufferey M, Steimle V, Reith W: CIITA is a transcriptional coactivator that is recruited to MHC class II promoters by multiple synergistic interactions with an enhanceosome complex. Genes Dev 2000, 14: $1156-1166$

28. Kadonaga JT, Tjian R: Affinity purification of sequence-specific DNA binding proteins. Proc Natl Acad Sci U S A 1986, 83:5889-5893

29. Dignam JD, Lebovitz RM, Roeder RG: Accurate transcription initiation by RNA polymerase II in a soluble extract from isolated mammalian nuclei. Nucleic Acids Res 1983, 11:1475-1489

30. O'Neill LP, Turner BM: Histone H4 acetylation distinguishes coding regions of the human genome from heterochromatin in a differentiation-dependent but transcription-independent manner. EMBO J 1995, 14:3946-3957

31. Imagawa S, Nakano Y, Obara N, Suzuki N, Doi T, Kodama T, Nagasawa T, Yamamoto M: A GATA-specific inhibitor (K-7174) rescues anemia induced by IL-1beta, TNF-alpha, or L-NMMA. FASEB J 2003, 17:1742-1744

32. Hu S, Luo Q, Cun B, Hu D, Ge S, Fan X, Chen F: The pharmacological NF-kappaB inhibitor BAY11-7082 induces cell apoptosis and inhibits the migration of human uveal melanoma cells. Int J Mol Sci 2012, 13:15653-15667

33. Umetani M, Nakao H, Doi T, Iwasaki A, Ohtaka M, Nagoya T, Mataki C, Hamakubo T, Kodama T: A novel cell adhesion inhibitor, K-7174, reduces the endothelial VCAM-1 induction by inflammatory cytokines, acting through the regulation of GATA. Biochem Biophys Res Commun 2000, 272:370-374

34. Irrera $\mathrm{N}$, Vaccaro $\mathrm{M}$, Bitto A, Pallio G, Pizzino G, Lentini M, Arcoraci V, Minutoli L, Scuruchi M, Cutroneo G, Anastasi GP, Ettari R, Squadrito F, Altavilla D: BAY 11-7082 inhibits the NFkappaB and NLRP3 inflammasome pathways and protects against IMQ-induced psoriasis. Clin Sci (Lond) 2017, 131:487-498

35. Zderic SA, Wein A, Rohrman D, Gong C, Nigro D, Haugaard N, Levin R: Mechanisms of bladder smooth-muscle hypertrophy and decompensation: lessons from normal development and the response to outlet obstruction. World J Urol 1998, 16:350-358

36. Stein R, Hutcheson JC, Krasnopolsky L, Canning DA, Carr MC, Zderic SA: The decompensated detrusor V: molecular correlates of bladder function after reversal of experimental outlet obstruction. J Urol 2001, 166:651-657

37. Zderic SA, Chacko S: Alterations in the contractile phenotype of the bladder: lessons for understanding physiological and pathological remodelling of smooth muscle. J Cell Mol Med 2012, 16:203-217

38. Lassmann J, Sliwoski J, Chang A, Canning DA, Zderic SA: Deletion of one SERCA2 allele confers protection against bladder wall hypertrophy in a murine model of partial bladder outlet obstruction. Am J Physiol Regul Integr Comp Physiol 2008, 294:R58-R65

39. Chang AY, Sliwoski J, Butler S, Hearn G, Lassmann J, Chacko S, Canning DA, Zderic SA: Calcineurin mediates bladder wall remodeling secondary to partial outlet obstruction. Am J Physiol Renal Physiol 2011, 301:F813-F822 
40. Vasquez E, Cristofaro V, Lukianov S, Burkhard FC, Gheinani AH, Monastyrskaya K, Bielenberg DR, Sullivan MP, Adam RM: Deletion of neuropilin 2 enhances detrusor contractility following bladder outlet obstruction. JCI Insight 2017, 2:e90617

41. Rohrmann D, Levin RM, Duckett JW, Zderic SA: The decompensated detrusor I: the effects of bladder outlet obstruction on the use of intracellular calcium stores. J Urol 1996, 156:578-581

42. Stein R, Hutcheson JC, Gong C, Canning DA, Carr MC, Zderic SA: The decompensated detrusor IV: experimental bladder outlet obstruction and its functional correlation to the expression of the ryanodine and voltage operated calcium channels. J Urol 2001, 165:2284-2288

43. Stein R, Gong C, Hutcheson JC, Canning DA, Zderic SA: The decompensated detrusor III: impact of bladder outlet obstruction on sarcoplasmic endoplasmic reticulum protein and gene expression. J Urol 2000, 164:1026-1030

44. Fang $\mathrm{P}$, Shi HY, Wu XM, Zhang YH, Zhong YJ, Deng WJ, Zhang YP, Xie M: Targeted inhibition of GATA-6 attenuates airway inflammation and remodeling by regulating caveolin-1 through TLR2/MyD88/NF-kappaB in murine model of asthma. Mol Immunol 2016, 75:144-150

45. Xia ZB, Meng FR, Fang YX, Wu X, Zhang CW, Liu Y, Liu D, Li GQ, Feng FB, Qiu HY: Inhibition of NF-kappaB signaling pathway induces apoptosis and suppresses proliferation and angiogenesis of human fibroblast-like synovial cells in rheumatoid arthritis. Medicine (Baltimore) 2018, 97:e10920

46. Bist A, Fielding PE, Fielding CJ: Two sterol regulatory element-like sequences mediate up-regulation of caveolin gene transcription in response to low density lipoprotein free cholesterol. Proc Natl Acad Sci U S A 1997, 94:10693-10698

47. Bist A, Fielding CJ, Fielding PE: p53 Regulates caveolin gene transcription, cell cholesterol, and growth by a novel mechanism. Biochemistry 2000, 39:1966-1972

48. van den Heuvel AP, Schulze A, Burgering BM: Direct control of caveolin-1 expression by FOXO transcription factors. Biochem J 2005, 385:795-802

49. Wang Y, Roche O, Xu C, Moriyama EH, Heir P, Chung J, Roos FC, Chen Y, Finak G, Milosevic M, Wilson BC, Teh BT, Park M, Irwin MS, Ohh M: Hypoxia promotes ligand-independent EGF receptor signaling via hypoxia-inducible factor-mediated upregulation of caveolin-1. Proc Natl Acad Sci U S A 2012, 109:4892-4897

50. Biederer CH, Ries SJ, Moser M, Florio M, Israel MA, McCormick F, Buettner R: The basic helix-loop-helix transcription factors myogenin and Id2 mediate specific induction of caveolin-3 gene expression during embryonic development. J Biol Chem 2000, 275: $26245-26251$

51. Martinez-Moreno M, Martinez-Ruiz A, Alvarez-Barrientos A, Gavilanes F, Lamas S, Rodriguez-Crespo I: Nitric oxide downregulates caveolin-3 levels through the interaction with myogenin, its transcription factor. J Biol Chem 2007, 282:23044-23054

52. Zhu B, Rippe C, Thi Hien T, Zeng J, Albinsson S, Stenkula KG, Uvelius B, Sward K: Similar regulatory mechanisms of caveolins and cavins by myocardin family coactivators in arterial and bladder smooth muscle. PLoS One 2017, 12:e0176759

53. Evans T, Reitman M, Felsenfeld G: An erythrocyte-specific DNAbinding factor recognizes a regulatory sequence common to all chicken globin genes. Proc Natl Acad Sci U S A 1988, 85:5976-5980

54. Orkin SH: GATA-binding transcription factors in hematopoietic cells. Blood 1992, 80:575-581

55. Moriguchi T, Suzuki M, Yu L, Takai J, Ohneda K, Yamamoto M: Progenitor stage-specific activity of a cis-acting double GATA motif for Gata1 gene expression. Mol Cell Biol 2015, 35:805-815

56. Kaneko H, Katoh T, Hirano I, Hasegawa A, Tsujita T, Yamamoto M, Shimizu R: Induction of erythropoietin gene expression in epithelial cells by chemicals identified in GATA inhibitor screenings. Genes Cells 2017, 22:939-952

57. Shimizu R, Yamamoto M: GATA-related hematologic disorders. Exp Hematol 2016, 44:696-705
58. Kaneko H, Shimizu R, Yamamoto M: GATA factor switching during erythroid differentiation. Curr Opin Hematol 2010, 17:163-168

59. Burch JB: Regulation of GATA gene expression during vertebrate development. Semin Cell Dev Biol 2005, 16:71-81

60. Kanematsu A, Ramachandran A, Adam RM: GATA-6 mediates human bladder smooth muscle differentiation: involvement of a novel enhancer element in regulating alpha-smooth muscle actin gene expression. Am J Physiol Cell Physiol 2007, 293:C1093-C1102

61. Lien CL, Wu C, Mercer B, Webb R, Richardson JA, Olson EN: Control of early cardiac-specific transcription of Nkx2-5 by a GATAdependent enhancer. Development 1999, 126:75-84

62. Molkentin JD: The zinc finger-containing transcription factors GATA-4, -5, and -6: ubiquitously expressed regulators of tissuespecific gene expression. J Biol Chem 2000, 275:38949-38952

63. Molkentin JD, Tymitz KM, Richardson JA, Olson EN: Abnormalities of the genitourinary tract in female mice lacking GATA5. Mol Cell Biol 2000, 20:5256-5260

64. Oh J, Wang Z, Wang DZ, Lien CL, Xing W, Olson EN: Target genespecific modulation of myocardin activity by GATA transcription factors. Mol Cell Biol 2004, 24:8519-8528

65. Xin M, Davis CA, Molkentin JD, Lien CL, Duncan SA, Richardson JA, Olson EN: A threshold of GATA4 and GATA6 expression is required for cardiovascular development. Proc Natl Acad Sci U S A 2006, 103:11189-11194

66. Chang DF, Belaguli NS, Iyer D, Roberts WB, Wu SP, Dong XR, Marx JG, Moore MS, Beckerle MC, Majesky MW, Schwartz RJ: Cysteine-rich LIM-only proteins CRP1 and CRP2 are potent smooth muscle differentiation cofactors. Dev Cell 2003, 4:107-118

67. Shirvani S, Xiang F, Koibuchi N, Chin MT: CHF1/Hey2 suppresses SM-MHC promoter activity through an interaction with GATA-6. Biochem Biophys Res Commun 2006, 339:151-156

68. Yin F, Herring BP: GATA-6 can act as a positive or negative regulator of smooth muscle-specific gene expression. J Biol Chem 2005, $280: 4745-4752$

69. Boopathi E, Hypolite JA, Zderic SA, Gomes CM, Malkowicz B, Liou HC, Wein AJ, Chacko S: GATA-6 and NF-kappaB activate CPI-17 gene transcription and regulate $\mathrm{Ca} 2+$ sensitization of smooth muscle contraction. Mol Cell Biol 2013, 33:1085-1102

70. Morrisey EE, Ip HS, Lu MM, Parmacek MS: GATA-6: a zinc finger transcription factor that is expressed in multiple cell lineages derived from lateral mesoderm. Dev Biol 1996, 177:309-322

71. Molkentin JD, Lu JR, Antos CL, Markham B, Richardson J, Robbins J, Grant SR, Olson EN: A calcineurin-dependent transcriptional pathway for cardiac hypertrophy. Cell 1998, 93:215-228

72. Molkentin JD, Olson EN: GATA4: a novel transcriptional regulator of cardiac hypertrophy? Circulation 1997, 96:3833-3835

73. van Berlo JH, Elrod JW, van den Hoogenhof MM, York AJ, Aronow BJ, Duncan SA, Molkentin JD: The transcription factor GATA-6 regulates pathological cardiac hypertrophy. Circ Res 2010, 107:1032-1040

74. Baeuerle PA, Baltimore D: NF-kappa B: ten years after. Cell 1996, $87: 13-20$

75. Karin M, Lin A: NF-kappaB at the crossroads of life and death. Nat Immunol 2002, 3:221-227

76. Shaw J, Yurkova N, Zhang T, Gang H, Aguilar F, Weidman D, Scramstad C, Weisman H, Kirshenbaum LA: Antagonism of E2F-1 regulated Bnip3 transcription by NF-kappaB is essential for basal cell survival. Proc Natl Acad Sci U S A 2008, 105:20734-20739

77. Bergdahl A, Sward K: Caveolae-associated signalling in smooth muscle. Can J Physiol Pharmacol 2004, 82:289-299

78. Balijepalli RC, Kamp TJ, Caveolae: ion channels and cardiac arrhythmias. Prog Biophys Mol Biol 2008, 98:149-160

79. Urban NH, Berg KM, Ratz PH: $\mathrm{K}+$ depolarization induces RhoA kinase translocation to caveolae and $\mathrm{Ca} 2+$ sensitization of arterial muscle. Am J Physiol Cell Physiol 2003, 285:C1377-C1385

80. Cohen AW, Park DS, Woodman SE, Williams TM, Chandra M, Shirani J, Pereira de Souza A, Kitsis RN, Russell RG, Weiss LM, 
Tang B, Jelicks LA, Factor SM, Shtutin V, Tanowitz HB, Lisanti MP: Caveolin-1 null mice develop cardiac hypertrophy with hyperactivation of p42/44 MAP kinase in cardiac fibroblasts. Am J Physiol Cell Physiol 2003, 284:C457-C474

81. Lee YH, Hwang MK, Morgan KG, Taggart MJ: Receptor-coupled contractility of uterine smooth muscle: from membrane to myofilaments. Exp Physiol 2001, 86:283-288

82. Gosens R, Stelmack GL, Dueck G, McNeill KD, Yamasaki A, Gerthoffer WT, Unruh H, Gounni AS, Zaagsma J, Halayko AJ: Role of caveolin-1 in p42/p44 MAP kinase activation and proliferation of human airway smooth muscle. Am J Physiol Lung Cell Mol Physiol 2006, 291:L523-L534

83. Darby PJ, Kwan CY, Daniel EE: Caveolae from canine airway smooth muscle contain the necessary components for a role in $\mathrm{Ca}(2+)$ handling. Am J Physiol Lung Cell Mol Physiol 2000, 279: L1226-L1235

84. Gosens R, Stelmack GL, Dueck G, Mutawe MM, Hinton M, McNeill KD, Paulson A, Dakshinamurti S, Gerthoffer WT, Thliveris JA, Unruh H, Zaagsma J, Halayko AJ: Caveolae facilitate muscarinic receptor-mediated intracellular $\mathrm{Ca} 2+$ mobilization and contraction in airway smooth muscle. Am J Physiol Lung Cell Mol Physiol 2007, 293:L1406-L1418

85. Couet J, Sargiacomo M, Lisanti MP: Interaction of a receptor tyrosine kinase, EGF-R, with caveolins: caveolin binding negatively regulates tyrosine and serine/threonine kinase activities. J Biol Chem 1997, 272:30429-30438

86. Yamamoto M, Toya Y, Jensen RA, Ishikawa Y: Caveolin is an inhibitor of platelet-derived growth factor receptor signaling. Exp Cell Res 1999, 247:380-388

87. Stehr M, Estrada CR, Khoury J, Danciu TE, Sullivan MP, Peters CA, Solomon KR, Freeman MR, Adam RM: Caveolae are negative regulators of transforming growth factor-beta1 signaling in ureteral smooth muscle cells. J Urol 2004, 172:2451-2455

88. Gosens R, Stelmack GL, Bos ST, Dueck G, Mutawe MM, Schaafsma D, Unruh H, Gerthoffer WT, Zaagsma J, Meurs H, Halayko AJ: Caveolin-1 is required for contractile phenotype expression by airway smooth muscle cells. J Cell Mol Med 2011, 15: $2430-2442$

89. Je HD, Gallant C, Leavis PC, Morgan KG: Caveolin-1 regulates contractility in differentiated vascular smooth muscle. Am J Physiol Heart Circ Physiol 2004, 286:H91-H98

90. Lin VK, McConnell JD: Molecular aspects of bladder outlet obstruction. Adv Exp Med Biol 1995, 385:65-74; discussion 75-79

91. Huang J, Wang T, Wright AC, Yang J, Zhou S, Li L, Small A, Parmacek MS: Myocardin is required for maintenance of vascular and visceral smooth muscle homeostasis during postnatal development. Proc Natl Acad Sci U S A 2015, 112: $4447-4452$

92. Sadegh MK, Ekman M, Rippe C, Sundler F, Wierup N, Mori M, Uvelius B, Sward K: Biomechanical properties and innervation of the female caveolin-1-deficient detrusor. Br J Pharmacol 2011, 162: $1156-1170$

93. Karbalaei MS, Rippe C, Albinsson S, Ekman M, Mansten A, Uvelius B, Sward K: Impaired contractility and detrusor hypertrophy in cavin-1-deficient mice. Eur J Pharmacol 2012, 689:179-185

94. Osman NI, Chapple CR, Abrams P, Dmochowski R, Haab F, Nitti V, Koelbl H, van Kerrebroeck P, Wein AJ: Detrusor underactivity and the underactive bladder: a new clinical entity? a review of current terminology, definitions, epidemiology, aetiology, and diagnosis. Eur Urol 2014, 65:389-398

95. Osman NI, Chapple CR: Are there pharmacotherapeutic options for underactive bladder? Eur Urol Focus 2018, 4:6-7 